\title{
AN OPTIMIZATION APPROACH TO EMPLOYEE SCHEDULING USING FUZZY LOGIC
}

\author{
A Thesis \\ presented to \\ the Faculty of California Polytechnic State University, \\ San Luis Obispo
}

\author{
In Partial Fulfillment \\ of the Requirements for the Degree \\ Master of Science in Industrial Engineering
}

By

William G. Spence

June 2011 
(C) 2011

William G. Spence

ALL RIGHTS RESERVED 


\title{
COMMITTEE MEMBERSHIP
}

TITLE:

\author{
AN OPTIMIZATION APPROACH TO \\ EMPLOYEE SCHEDULING USING \\ FUZZY LOGIC
}

AUTHOR:

William G. Spence

DATE SUBMITTED:

June 2011

Faculty Advisory Committee:

COMMITTEE CHAIR:

Dr. Tali Freed

COMMITTEE MEMBER:

Dr. Sema Alptekin

COMMITTEE MEMBER:

Dr. Roya Javadpour 


\begin{abstract}
An Optimization Approach to Employee Scheduling Using Fuzzy Logic William G. Spence
\end{abstract}

Selection of sales employees is critical because the sales employees represent the company's image, competitive advantage, technology, and values. In many service systems the majority of consumer contact is with the sales department. Since there are different types of customers, scheduling quality salespersons who can adequately help consumers may affect revenue.

This thesis proposes a new methodology for the scheduling of employees in a service system. The methodology uses Fuzzy Logic to calculate possible sales and Linear Programming to create an optimal schedule. This approach enables the rating of sales employees with respect to three customer's types (Lookie Lou, Price Shopper and Buyer). The salesperson rating, along with customer arrival distribution is then used to optimize sale person scheduling, with the objective of revenue maximization. The uniqueness of this thesis lies in the combination of Fuzzy Logic and Linear Programming. The combination of these two disciplines provides an adaptive tool that can be used to optimize employee scheduling based on personality traits. 


\section{ACKNOWLEDGMENTS}

I would like to first thank the members of my committee, Dr. Tali Freed, Dr. Sema Alptekin and Dr. Roya Javadpour for their continuous commitment to quality and tireless contributions for a better Industrial Engineering Department. Your encouragement and patience during the last 5 years were fundamental in the development of this work.

I dedicate this work to my parents and family, because all that I am I owe it to them. Their infinite love and understanding will forever be the guidelines in my life.

And finally to Adair, the love of my life, you make me want to reach for the stars. Thank you for the constant support and encouragement. You inspire me every day. 


\section{TABLE OF CONTENTS}

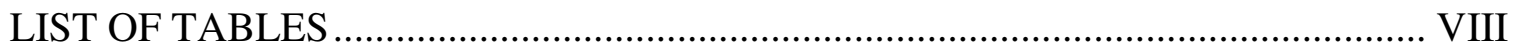

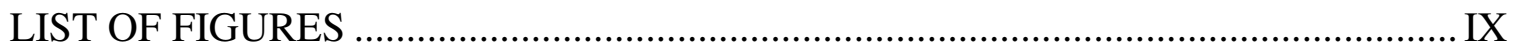

\section{CHAPTER}

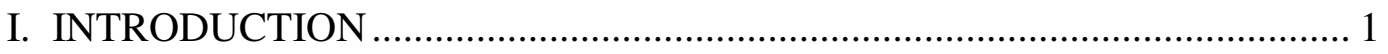

II. LITERATURE REVIEW ................................................................. 3

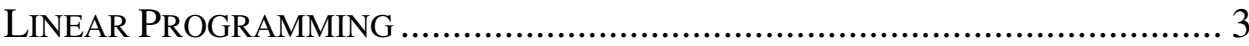

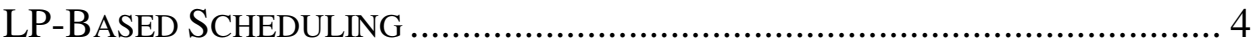

Scheduling Example ...................................................................... 5

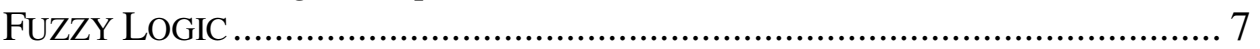

FUZZY LOGIC SYSTEMS ................................................................... 10

Types of Fuzzy Logic.............................................................. 10

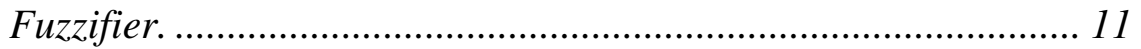

Fuzzy Sets. ............................................................... 11

Membership Functions.................................................................. 13

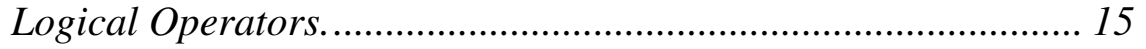

If / Then Rules. ....................................................................... 15

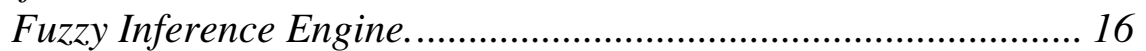

Output Processor.................................................................... 18

Defuzzifier. ................................................................... 19

Fuzzy Logic Example. ……………………………................... 20

APPLICATIONS OF FUZZY LOGIC …………………………………….... 22

PERSONALITY TRAITS OF SALESPERSONS .................................................. 23

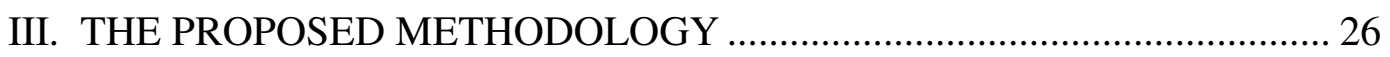

Performance CRITERIA AND Data Collection.................................... 29

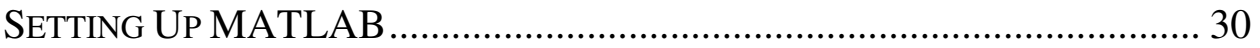

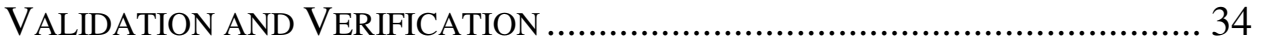

LINEAR PROGRAMMING FoRMULATION................................................... 35

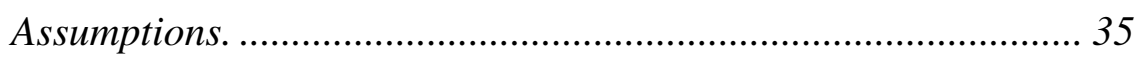

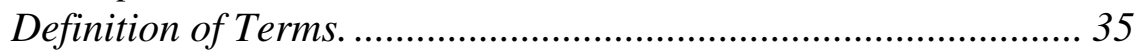

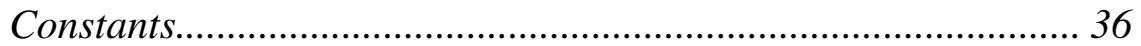

Variables........................................................................... 37

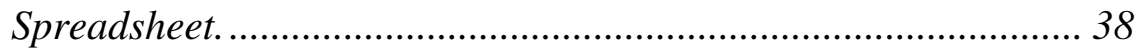

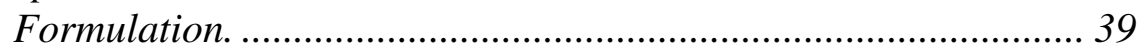

Objective Function............................................................ 39

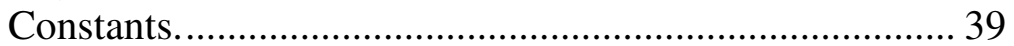

Constraints. ..................................................................... 39

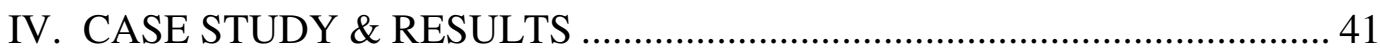

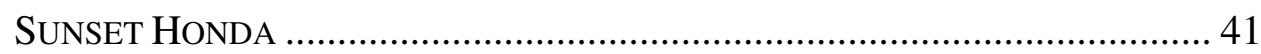

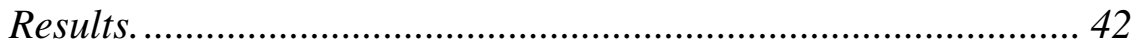

ADAPTABILITY TO OTHER BUSINESSES .................................................. 43 
V. CONCLUSION AND FURTHER STUDY ........................................... 44

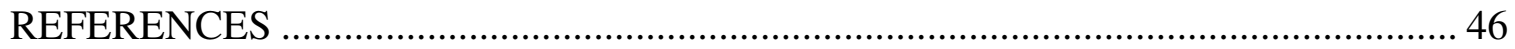

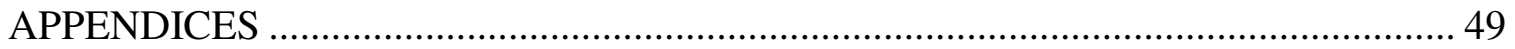

A. MEMBERSHIP FUNCTION INTERSECTIONS .................................... 50

B. ENERGY LEVEL MEMBERSHIP FUNCTION .................................. 51

C. EXPERIENCE MEMBERSHIP FUNCTION ...................................... 52

D. PERSONALITY MEMBERSHIP FUNCTION .................................... 53

E. SELF-CONFIDENCE MEMBERSHIP FUNCTION .............................. 54

F. COMMUNICATION SKILLS MEMBERSHIP FUNCTION ....................... 55

G. COMMITMENT MEMBERSHIP FunCTION....................................... 56

H. RESULT MEMBERSHIP FUNCTION............................................. 57

I. RELATIVE LIKELIHOOD OF CLOSING A SALE................................ 58

J. DETAILED LP FORMULATION ................................................... 59 


\section{LIST OF TABLES}

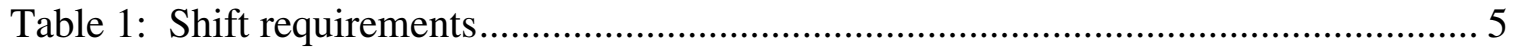

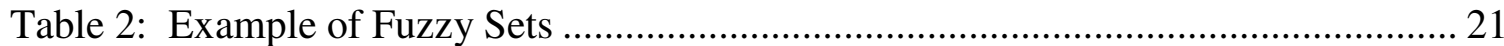

Table 3: Partial list of Fuzzy Logic real world applications ........................................ 23

Table 4: Number of rules based on Fuzzy Sets and variables ...................................... 31

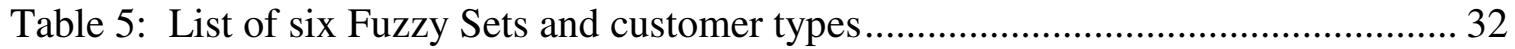

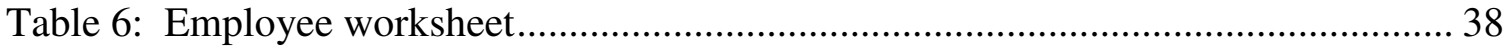




\section{LIST OF FIGURES}

Figure 1: Type-1 Fuzzy Logic System (FLS) …………….......................................... 11

Figure 2: Continuous time plot of crisp and Fuzzy Sets .................................................. 13

Figure 3: Membership functions defining "experience"................................................ 14

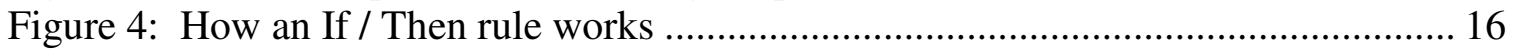

Figure 5: Fuzzy Inference System ....................................................................... 17

Figure 6: Maximum defuzzifer ............................................................................. 19

Figure 7: Mean of maxima defuzzifier ............................................................. 19

Figure 8: Centrold defuzzifier............................................................................... 20

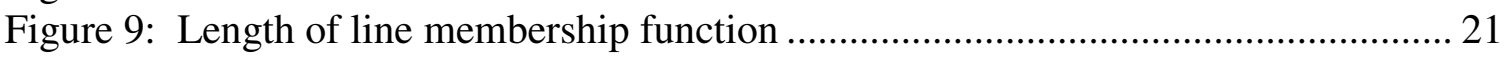

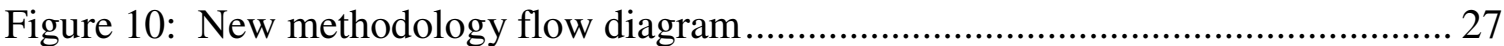

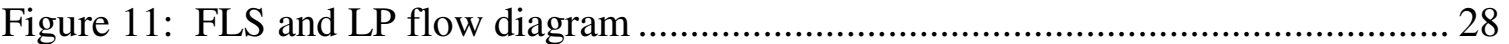

Figure 12: Example membership function................................................................ 32 


\section{CHAPTER I}

\section{INTRODUCTION}

It is easy to assume that every business owner wants the ability to know how to schedule employees to maximize sales. This thesis dissects what characteristics are needed to be a great salesperson, and uses those characteristics to create a schedule that maximizes estimated sales. Using this methodology a manager can schedule salespersons and estimate the resulting sales simultaneously.

The methodology developed in this research includes the following steps:

1. Based on expert knowledge generate:

a. Set of employee characteristics

b. Set of customer characteristics

2. Develop a Fuzzy Logic model representing customer and employee characteristics as input to the likelihood of sales

3. Determine arrival rates of the various types of customers

4. Develop a Linear Program incorporating the Fuzzy Logic model findings in order to determine salespersons' scheduling such that total sales revenue is "optimized"

This thesis combines three main topics: Fuzzy Logic Systems, Linear Programming Optimization, and models of Sales systems. The Literature Review will provide background on each topic in order to build a fundamental base for understanding the methodology created. The use of simplified examples in the overview chapter will help with this understanding. After a level of understanding is created, the new methodology 
will be presented and finally the interrelationships examined validated and verified. The thesis will conclude with a case study. We hope that this research and its future extensions will be adapted as a scheduling methodology to many sales environments. 


\section{CHAPTER II}

\section{LITERATURE REVIEW}

The Literature Review is divided into three sections. The first section discusses Linear Programming, the second describes Fuzzy Logic, and finally personality traits of sales people and their effect on sales success and revenue are examined.

\section{Linear Programming}

A linear programming (LP) problem is the problem of maximizing or minimizing a linear function subject to linear constraints. The constraints may be equalities or inequalities. The LP model has been applied in a large number of areas including military applications, transportation and distribution, scheduling, production and inventory management, telecommunication, agriculture and more. "Many problems simply lend themselves to a LP solution but in many cases some ingenuity is required for the modeling” (Megiddo and Dyer 1997).

Linear Programming is broad enough to encompass many interesting and important applications, yet specific enough to be tractable even if the number of variables is large. Linear programming was developed in the 1940 's, motivated initially by the need to solve complex planning problems in wartime operations. The founders are George B. Dantzig, who devised the Simplex method in 1947, and John von Neumann, who established the Theory of Duality that same year.

Many industries use linear programming as a standard tool, e.g. to allocate a finite set of resources in an optimal way. Examples of important application areas include airline crew scheduling, shipping or telecommunication networks, oil refining and blending, and 
stock and bond portfolio selection.

\section{LP-Based Scheduling}

How to schedule employees has been an ongoing battle with employers. Having unqualified or inexperienced staff working during peak hours seems to be a perpetual problem. How should employees be scheduled to maximize sales? Experts explain that historical data is the most important piece of information to proper scheduling. The types of customers showing up, the quantity of each customer type and the number of employees needed to meet customer demands are all examples of what information can be derived from historical data. Application of LP to personnel scheduling can be found in Operation Research or Management Science textbooks such as Operations Research, by Winston, (2003), Introduction to Operations Research by Hillier and Lieberman (2009), or Managerial Decision Modeling by Balakrishnan, Render, and Stair (2006). Most of these applications require use of solution software.

Some LP-based solution algorithms to personnel scheduling have been developed that do not require LP software. For example, Tibrewala, Philippe, and Brown (1972) develop a technique for scheduling a seven-day operation giving employees two consecutive days off. The method is designed to be easily understood so a wide range of audiences can use it. "The algorithm proven here is important, however, in that it requires neither the large mathematical structure of linear programming, nor access to a computer to obtain solutions. A procedure that can be applied by any clerk following a simple set of rules is proven optimal using only logic. This is important since the problem solved is of wide applicability and must usually be handled by "nonmathematical" personnel" Tibrewala et al., (1972). 


\section{Scheduling Example}

This example is taken from the 1993 UG Exam at Brunel University, Uxbridge, West London, UK. (http://people.brunel.ac.uk/ mastjjb/jeb/or/lpmore.html).

The production manager of a chemical plant is attempting to devise a shift pattern for his workforce (currently 60 workers). Each day of every working week is divided into three eight-hour shift periods (00:01-08:00, 08:01-16:00, 16:01-24:00) denoted by night, day and late respectively. The plant must be manned at all times and the minimum number of workers required for each of these shifts over any working week shown in Table 1:

\begin{tabular}{|c|c|c|c|c|c|c|c|}
\cline { 2 - 8 } \multicolumn{1}{c|}{} & Mon & Tues & Wed & Thur & Fri & Sat & Sun \\
\hline Night & 5 & 3 & 2 & 4 & 3 & 2 & 2 \\
\hline Day & 7 & 8 & 9 & 5 & 7 & 2 & 5 \\
\hline Late & 9 & 10 & 10 & 7 & 11 & 2 & 2 \\
\hline
\end{tabular}

The union agreement governing acceptable shifts for workers:

1. Each worker is assigned to work either a night shift or a day shift or a late shift and once a worker has been assigned to a shift they must remain on the same shift every day that they work.

2. Each worker works four consecutive days during any seven day period. 
Solution:

Variables

Workers can only start their four consecutive work days on one of the seven days (Mon to Sun) and in one of the three eight-hour shifts (night, day, late).

Let:

$\mathrm{i}=$ Days of week:

$\begin{array}{lll}1 & =\text { Monday } & 5=\text { Friday } \\ 2 & =\text { Tuesday } & 6=\text { Saturday } \\ 3 & =\text { Wednesday } & 7=\text { Sunday } \\ 4 & =\text { Thursday }\end{array}$

$\mathrm{j}=$ Shift

$1=$ Night

$2=$ Day

$3=$ Late

$\mathrm{N}_{\mathrm{ij}}$ = number of workers starting their four consecutive work days on day $\mathrm{i}$ and shift $\mathrm{j}$.

$D_{i j}=$ number of workers required on day $i$ and shift period $j$

Objective

Minimize $\Sigma\{\mathrm{i}=1$ to 7$\} \Sigma\{\mathrm{j}=1$ to 3$\} \mathrm{N}_{\mathrm{ij}}$ 


\section{Constraints}

Upper limit on the total number of workers of 60 :

$$
\Sigma\{i=1 \text { to } 7\} \Sigma\{j=1 \text { to } 3\} N_{i j}<=60
$$

Lower limit on the total number of workers required for each day/shift period:

$$
\begin{aligned}
& \text { Monday: } \mathrm{N}_{1 \mathrm{j}}+\mathrm{N}_{7 \mathrm{j}}+\mathrm{N}_{6 \mathrm{j}}+\mathrm{N}_{5 \mathrm{j}}>=\Sigma\{\mathrm{j}=1 \text { to } 3\} \mathrm{D}_{1 \mathrm{j}} \\
& \text { Tuesday: } \mathrm{N}_{2 \mathrm{j}}+\mathrm{N}_{1 \mathrm{j}}+\mathrm{N}_{7 \mathrm{j}}+\mathrm{N}_{6 \mathrm{j}}>=\Sigma\{\mathrm{j}=1 \text { to } 3\} \mathrm{D}_{2 \mathrm{j}} \\
& \text { Wednesday: } \mathrm{N}_{3 \mathrm{j}}+\mathrm{N}_{2 \mathrm{j}}+\mathrm{N}_{1 \mathrm{j}}+\mathrm{N}_{7 \mathrm{j}}>=\Sigma\{\mathrm{j}=1 \text { to } 3\} \mathrm{D}_{3 \mathrm{j}} \\
& \text { Thursday: } \mathrm{N}_{4 \mathrm{j}}+\mathrm{N}_{3 \mathrm{j}}+\mathrm{N}_{2 \mathrm{j}}+\mathrm{N}_{1 \mathrm{j}}>=\Sigma\{\mathrm{j}=1 \text { to } 3\} \mathrm{D}_{4 \mathrm{j}} \\
& \text { Friday: } \quad \mathrm{N}_{5 \mathrm{j}}+\mathrm{N}_{4 \mathrm{j}}+\mathrm{N}_{3 \mathrm{j}}+\mathrm{N}_{2 \mathrm{j}}>=\Sigma\{\mathrm{j}=1 \text { to } 3\} \mathrm{D}_{5 \mathrm{j}} \\
& \text { Saturday: } \mathrm{N}_{6 \mathrm{j}}+\mathrm{N}_{5 \mathrm{j}}+\mathrm{N}_{4 \mathrm{j}}+\mathrm{N}_{3 \mathrm{j}}>=\Sigma\{\mathrm{j}=1 \text { to } 3\} \mathrm{D}_{6 \mathrm{j}} \\
& \text { Sunday: } \quad \mathrm{N}_{7 \mathrm{j}}+\mathrm{N}_{6 \mathrm{j}}+\mathrm{N}_{5 \mathrm{j}}+\mathrm{N}_{4 \mathrm{j}}>=\Sigma\{\mathrm{j}=1 \text { to } 3\} \mathrm{D}_{7 \mathrm{j}}
\end{aligned}
$$

\section{Fuzzy Logic}

Fuzzy Logic (FL) is based on Fuzzy Set Theory that was established by Lofti A. Zadeh in 1965 (Zadeh 1985, Cox 1993, Barron 1993). A human being, when faced with incomplete and uncertain information, is able to sift through evidence and arrive at some sort of conclusion, uncertain perhaps, but sufficient to guide him or her through practical decisions (Mamdani and Assilian 1975, Zadeh 1985, Zadeh 1992). When faced with inconsistent and partial information, classical logic fails. When that happens all proposition are treated the same, neither is more true or false than the other. 
Fuzzy Sets are classes with fuzzy boundaries in which the transition from membership to non membership is more gradual than abrupt (Zadeh 1965, Braae and Rutherford 1979, Zadeh 1985). This means that a fuzzy set can accommodate a "normal" distribution of items falling within a membership category, so that an item could be a member to a degree defined in the range of zero to one.

Lotfi Zadeh, the "Father of Fuzzy Logic", has stated in his publication, Fuzzy Logic, Neural Networks, and Soft Computing (1994), "In a broad sense, Fuzzy Logic is almost synonymous with fuzzy set theory. Fuzzy set theory, as its name suggests, is basically a theory of classes with unsharp boundaries." Zadeh went on further to say, "What is important to recognize is that any crisp theory can be fuzzified by generalizing the concept of a set within that theory to the concept of a fuzzy set."

MATLAB's Fuzzy Logic Tutorial lists the following observations about Fuzzy Logic (2010).

- Fuzzy Logic is conceptually easy to understand

- Fuzzy Logic is flexible.

- Fuzzy Logic is tolerant of imprecise data

- Fuzzy Logic can model nonlinear functions of arbitrary complexity

- Fuzzy Logic can be built on top of the experience of experts

- Fuzzy Logic can be blended with conventional control techniques

- Fuzzy Logic is based on natural language 
Mendel (1995) added these thoughts about Fuzzy Logic. "It is an important tool for two main reasons:

1. It allows us to form a model of what is going on when decisions are made. Having a model can help us to understand more about our decision making processes and learn how to make the best possible decisions.

2. Can use Fuzzy Logic to design computers that can actually make decisions."

Fuzzy Logic's main objective is to "model and minimize the effect of uncertainties" (Mendel, 2001). Fuzzy Logic mimics human decision-making and the ability to generate crisp solutions from inexact information. "Fuzzy Logic arose from the desire to emulate human thought processes that are imprecise, deliberate, uncertain, and usually expressed in linguistic terms. In addition, human ways of reasoning are approximate, nonquantitative, linguistic, and dispositional” (Kecman 2001). When a problem becomes too complicated to comprehend, the problem becomes uncertain.

Before Zadeh conceived Fuzzy Logic, traditional computing methods tried to categorize information into yes / no, black / white, true / false, 0 / 1, or all / nothing statements. In contrast to classical knowledge systems, Fuzzy Logic is aimed at a formalization of modes of reasoning that are approximate rather than exact (Kosko 1992). It builds upon the assumption that all things consist of degrees on a sliding scale. Fuzzy Logic can account for height, weight, temperature (hot or cold), color, or anything else affected by human behavior and/or opinion. A brief list of its advantages, taken from Kecman (2001), is below:

1. Human knowledge is available 
2. A mathematical model is unknown or impossible to obtain

3. The process is substantially nonlinear

4. There is a lack of precise sensor information

5. It is applied at the higher levels of hierarchical control systems

6. It is applied in generic decision-making processes

\section{Fuzzy Logic Systems}

Types of Fuzzy Logic. Two forms of knowledge are:

- Objective Knowledge is mathematical models / problem formulations

- Subjective Knowledge which represents linguistic information.

When these two forms of knowledge are coordinated in a logical way we get a Fuzzy Logic System. "A Fuzzy Logic System is a nonlinear mapping of an input data vector into a scalar output, the vector output case decomposes into a collection of independent multi-input / single-output system" (Mendel 2001).

Fuzzy Logic Systems contain four components:

1. Fuzzifier

2. Inference Engine

3. Rules

4. Output Processor

Each of these components is a standalone entity in the Fuzzy Logic system, but work as a whole to take crisp inputs and make crisp outputs.

This methodology uses Fuzzy Sets that are type-1. Type-1 Fuzzy Sets are described by membership functions that are totally certain. Figure 1 below is a type-1 Fuzzy Logic system. 


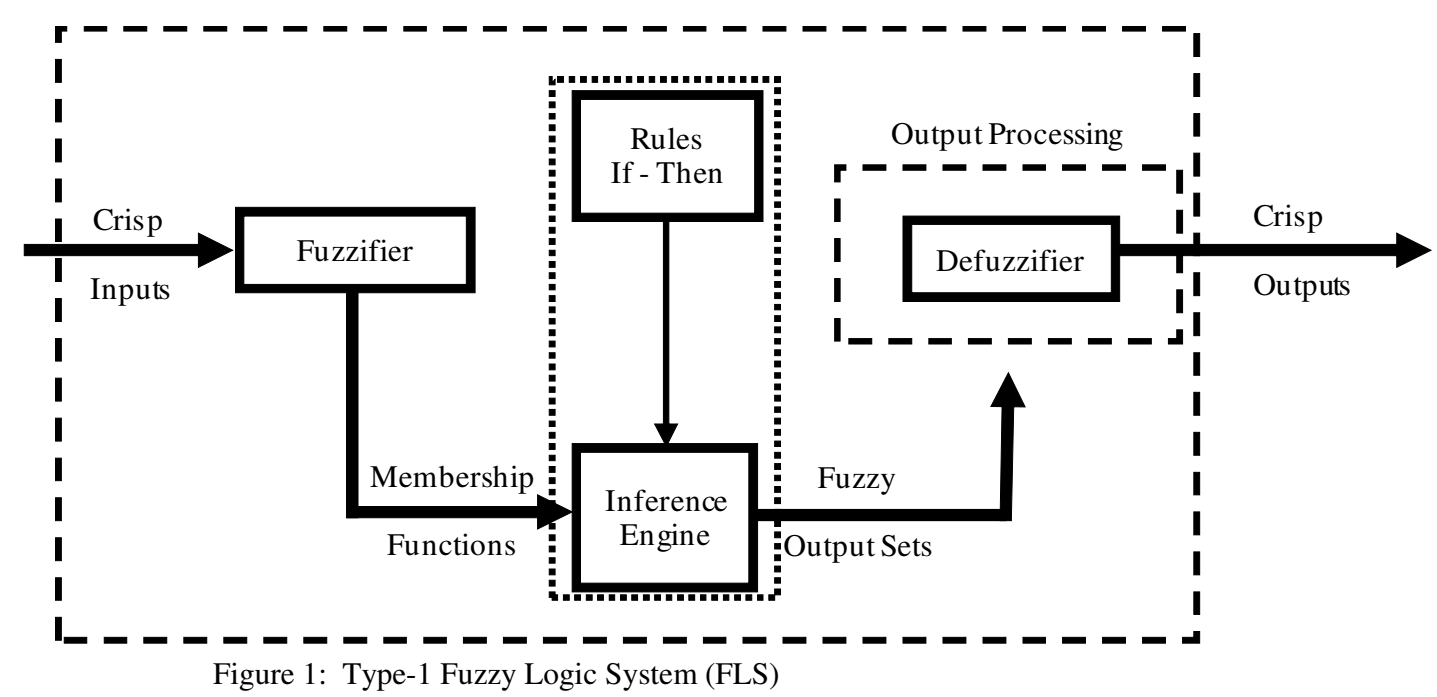

As mentioned above, Fuzzy Logic Systems have four components (fuzzifier, inference engine, rules, and output processor). The next few sections will dissect Figure 1.

Fuzzifier. The fuzzifier maps a crisp input into type-1 Fuzzy Sets and then membership functions. "It is needed in order to activate rules which are in terms of linguistic variables, which have Fuzzy Sets associated with them" (Mendel, 1995).

Fuzzy Sets. To understand what a Fuzzy Set is, an explanation of a "classical set" needs to be established. A classical set completely includes or excludes any given element. Classical sets state X must either be in set A or in set not-A. Fuzzy Set allows X to be in both set A and set not-A (Fuzzy Logic Toolbox; MatLab user guide 2010). A simple example would be the personality characteristics that make up a good salesperson. Researchers would agree that it takes specific characteristics to make a great salesperson but what are those characteristics and how can they be agreed upon? Most would agree that product knowledge and great communication skills belong to the "set of great sales characteristics", but what about trustworthiness or physical appearance or even motivation? Some researchers feel they should be part of set "great sales characteristics" 
but some will disagree. This basic example demonstrates that sharp edged yes-no logic stops being useful and a logic that could handle this uncertainty needs to be used. A fuzzy set is the beginning and the foundation of Fuzzy Logic. A fuzzy set is a set without a crisp, clearly defined boundary, and can contain components with a fractional degree of membership. In Fuzzy Logic, the truth of any statement becomes a matter of degree; any statement can be fuzzy. Fuzzy reasoning gives the ability to reply to a yes-no question with a not-quite-yes-or-no answer (Fuzzy Logic Toolbox; MatLab user guide 2010).

If we represent "truth / yes" a value of 1 and "false / no" the value of 0, Fuzzy Logic allows in-between values like 0.4 and 0.7398 . "A fuzzy set is a generalization of an ordinary subset (i.e. a crisp subset) whose membership function only takes on two values, zero or unity" (Mendel 1995). Continuing the example from above about what characteristics make up a great salesperson, the following logic would apply to this example.

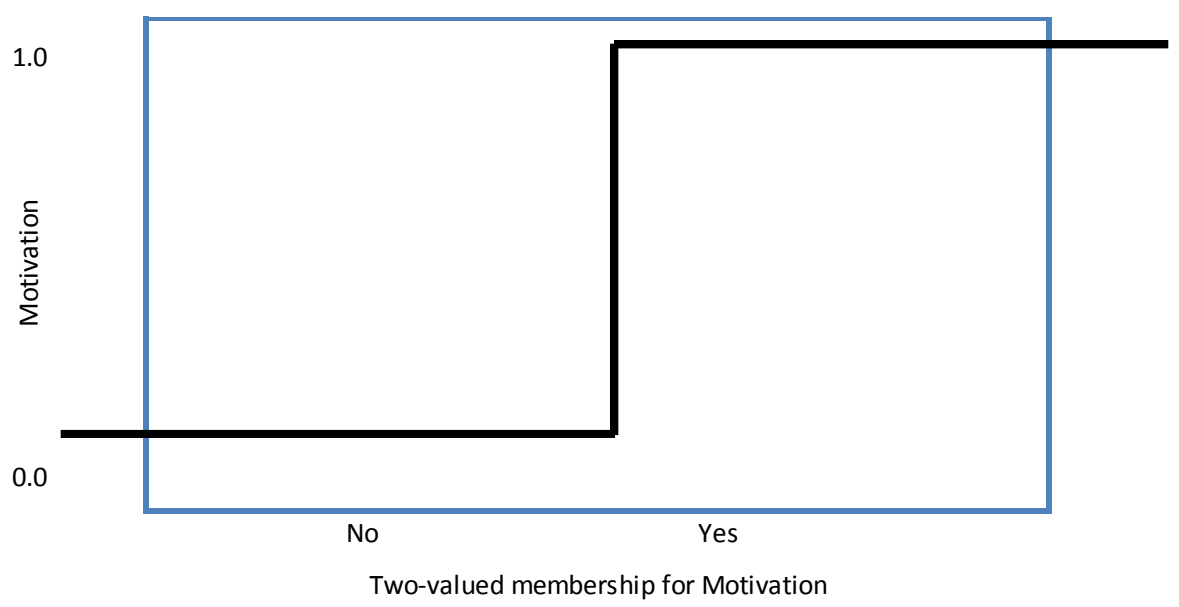




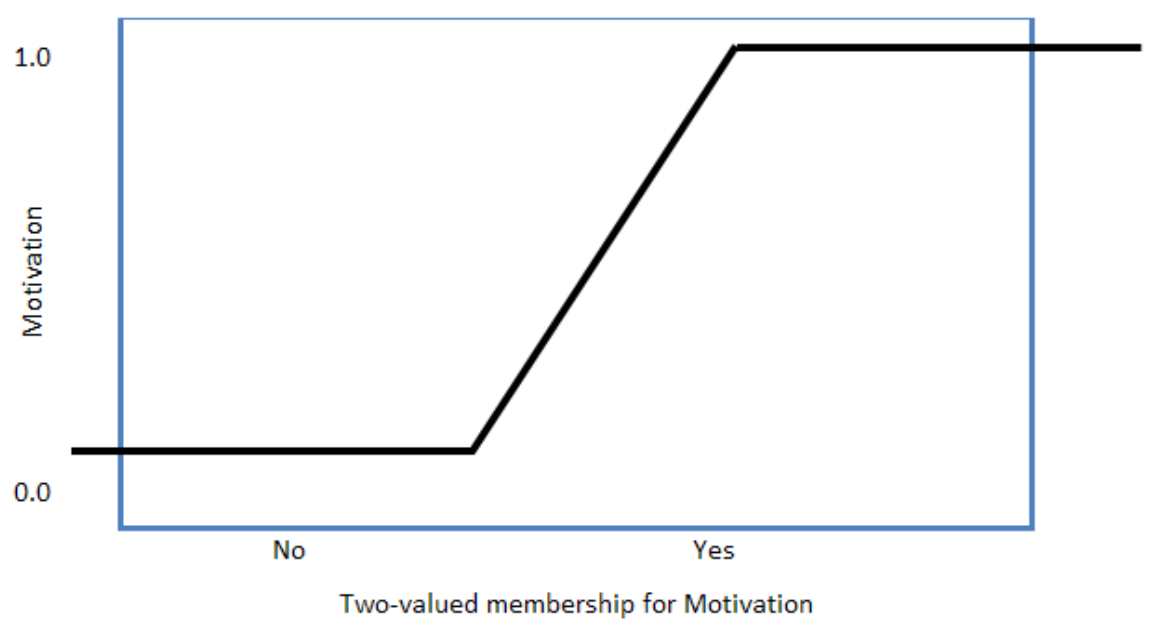

Figure 2: Continuous time plot of crisp and Fuzzy Sets

Figure 2 above, on the top, is a continuous time plot showing the truth-values for "Motivation." If forced to respond with an absolute yes or no response, the graph on the top shows a value of 1 if the employee has motivation and 0 for no motivation which does not correctly mimic real world human thinking. The bottom graph of Figure 2 is the same continuous time plot showing the truth-value for motivation if allowed to respond with fuzzy in-between values. "The main point of this example is to demonstrate that in Fuzzy Logic an element can reside in more than one set to different degrees of similarity. This can not occur in crisp set theory" (Mendel 1995).

Membership Functions. A membership function (MF) is a curve that defines how each point in the input space is mapped to a membership value (or degree of membership) between 0 and 1. An example Fuzzy Set from this research is, the Fuzzy Set "Experience." In this case, all potential experience levels, say from Year 1 to Year 30, and the word "experienced" would correspond to a curve that defines the degree to which any person is experienced. A smooth curve should be developed that goes from not-experienced to experienced where it would level off. "This is represented as a continuous value between 0 to 1 where 0 is false, 1 is true, and .5 indicates we are 
halfway certain. The mapping from a numeric value to a degree of truth for a linguistic value is done by the membership function" (Diao 2002). The curve below, in Figure 3 , defines the transition from "not experienced" to "experienced". The top image is a sharp line, which as discussed earlier is unreasonable, and the bottom membership function is more accepted by Fuzzy Logic experts.
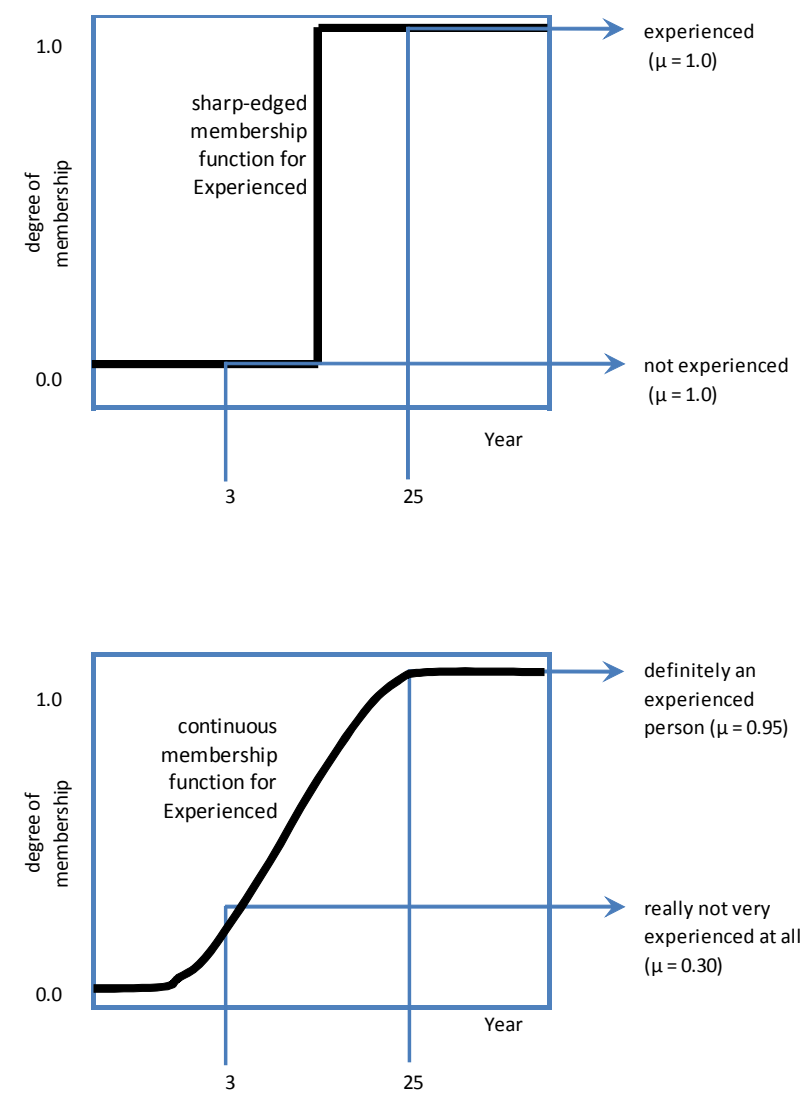

Figure 3: Membership functions defining "experience"

The membership functions in Figure 3 are two examples of what shapes Membership functions can take. The most common and simplest shapes are: triangular, bell, trapezoidal and exponential shapes. "In engineering applications of Fuzzy Logic, membership functions are, for the most part, associated with terms that appear in the antecedents or consequents of rules, or in phrases" (Mendel 1995). The terms antecedent and consequent are explained later in this chapter. 
Logical Operators. Fuzzy Logic reasoning is a superset of standard Boolean logic. Because of this relationship, the fuzzy values only need to be held by their extreme boundaries of 1 and 0 , standard logical operations will hold. Recalling from the last section on membership functions, in Fuzzy Logic the truth of any statement is a matter of degree, instead of the truth-values being held at 1 or 0 , the input values can be real numbers between 0 and 1 . The other difference is the use of intersection, union, and the complement operators such as "MIN(A,B), MAX $(A, B)$ and 1-A" instead of the "A AND B, A OR B and NOT A" (Kecman 2001). Since there is now a function behind the truth table, values other than 1 and 0 can be taken into consideration. There are other operators than "MIN(A,B), MAX(A,B) and 1-A", but these are the most commonly used ones for engineering applications (Kecman 2001).

If / Then Rules. Rules are the engine that drive the system. The rules being used throughout this research are a collection of If / Then statements. "One must be able to articulate, to structure, the human solution in the language of fuzzy rules. Almost all structured human knowledge can be expressed in the form of If / Then rules" (Kecman, 2001). A fuzzy If / Then rule assumes (or takes) the form:

\section{If $\mathrm{x}$ is $\mathrm{A}$ then $\mathrm{y}$ is $\mathrm{B}$}

Where A and B are linguistic values defined by Fuzzy Sets on the ranges $\mathrm{X}$ and $\mathrm{Y}$. The if-part of the rule "x is A" is called the antecedent, while the then-part of the rule "y is B" is called the consequent or conclusion. Figure 4 shows how If / Then rules work with Membership Functions. 


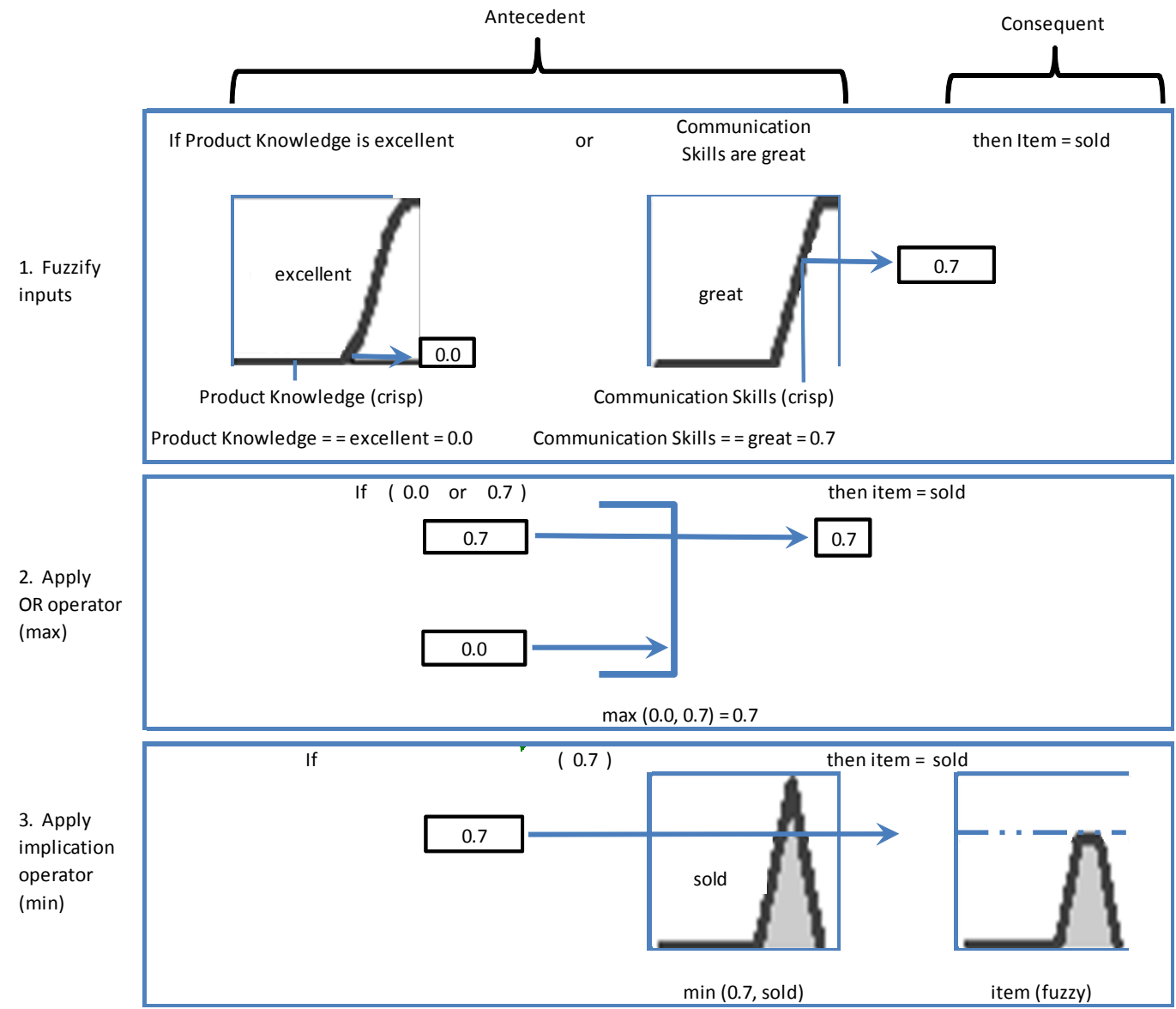

Figure 4: How an If / Then rule works

Figure 4 is a simple example of how an if/then rule is used in a Fuzzy Logic System. The rule is: "If Product Knowledge is excellent or Communication Skills are great then the item is sold." In this example, Product Knowledge (excellent) is equal to a 0 on the membership function and Communication Skills (great) is equal to a .7 on the membership function. After applying the "or" operator, and taking the maximum of the two numbers from the membership function, .7 becomes the input value to the "sold" membership function. In the lower right hand corner of Figure 5, the resulting membership function is shown after applying the minimum implication operator.

Fuzzy Inference Engine. Fuzzy inference is the process of formulating the mapping from a given input to an output using Fuzzy Logic. The mapping then provides 
a basis from which decisions can be made, or patterns distinguished. "Fuzzy inference is the kernel in a Fuzzy Logic system. It has the capability of simulating human decision making based on fuzzy concepts” (Begg, Palaniswami 2006). The process of fuzzy inference involves all of the pieces that are described in the previous sections: membership functions, Fuzzy Logic operators, and If / Then rules. "In a type-1 Fuzzy Logic system, the inference engine combines rules and gives a mapping from input type1 Fuzzy Sets to output type-1 Fuzzy Sets.” (Karnik 1999).

Fuzzy inference systems are also known as fuzzy-rule-based systems, fuzzy models or fuzzy controllers. A fuzzy inference system is composed of five functional blocks (see Figure 5 below):

1. A rule base containing a number of fuzzy If / Then rules

2. A database which defines the membership functions of the Fuzzy Sets used in the fuzzy rules

3. A decision-making unit which performs the inference operation on the rules

4. A fuzzification interface which transforms the crisp inputs into degrees of match with linguistic values

5. A defuzzification interface which transform the fuzzy results of the inference into a crisp output

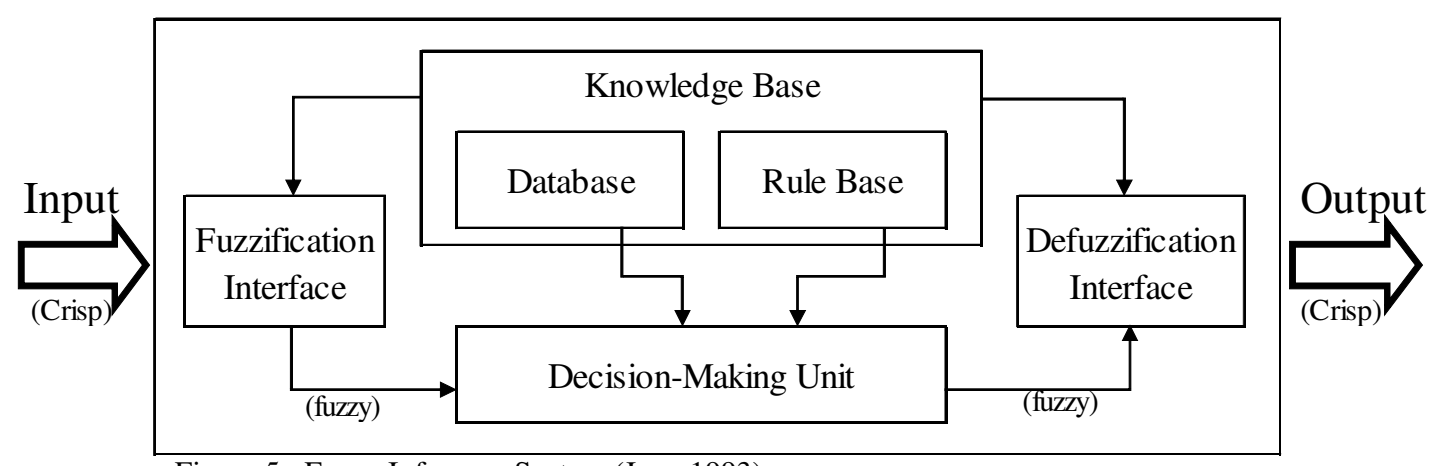

Figure 5: Fuzzy Inference System (Jang 1993) 
It is common for the rule base and the database are jointly referred to as the knowledge base. The steps of fuzzy reasoning (inference operations upon fuzzy If / Then rules) performed by fuzzy inference systems are:

1. Compare the input variables with the membership functions on the antecedent, to obtain the membership values of each linguistic label.

2. Combine the membership values on the antecedent to get the firing strength (weight) of each rule. From the example in Figure 4, the firing strength of each rule is 0.0 and 0.7 . Taking the maximum of the two numbers leaves 0.7 as the firing strength the rule.

3. Generate the qualified consequent (either fuzzy or crisp) of each rule.

4. Aggregate the qualified consequents to produce a crisp output. Referring back to the example in Figure 4 the firing strength (0.7) intersects the sold membership function towards the top. The result can be seen in the lower right corner of the figure. What is left of the membership function will be used to produce a crisp output.

Several types of fuzzy reasoning have been proposed in the literature. Depending on the types of fuzzy reasoning and fuzzy If / Then rules employed, there are two types of fuzzy inference systems that can be implemented: Mamdani-type and Sugeno-type. These two types of inference systems vary somewhat in the way outputs are determined. Takagi and Sugeno's fuzzy If / Then rules are going to be the method used in this research.

Output Processor. In a type-1 Fuzzy Logic System an output processor as a single entity having the sole purpose of producing crisp numbers using the defuzzifier, and is known as defuzzification. A crisp output is obtained from a type-1 set. 
Defuzzifier. The Defuzzifier performs the following functions:

1. Converts the range of values of output variables.

2. Defuzzification.

A Defuzzifier produces a crisp output for our Fuzzy Logic system from the output of the inference block. The candidates for defuzzifiers are shown graphically in Figures 6 through 8 .

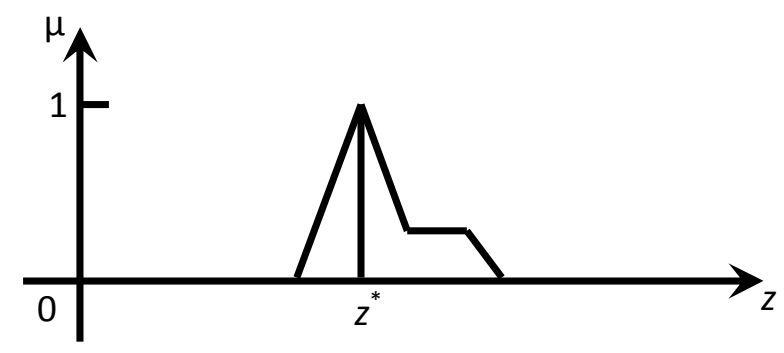

Figure 6: Maximum defuzzifer (Mendel 1995)

a. Maximum defuzzifier - Examines the Fuzzy Set B and chooses as its output the value of for which is a maximum.

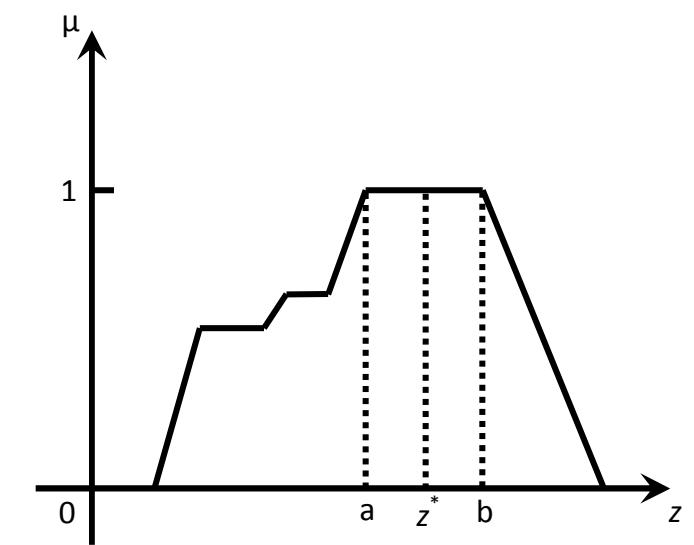

Figure 7: Mean of maxima defuzzifier (Mendel 1995)

b. Mean of maxima defuzzifier - Examines the Fuzzy Set B and first determines the values of " $\mu$ " for which it is a maximum. It then computes the mean of these values as its output. 


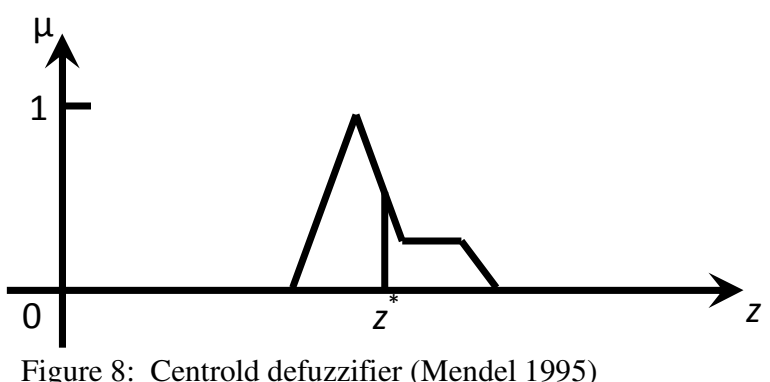

c. Centroid defuzzifier - Determines the centre of gravity of the final fuzzy control space, and uses this value as the output.

The centroid defuzzifier is the most commonly used method. For more information on defuzzifiers the reader is referred to "Fuzzy Logic Systems for Engineering: A Tutorial," by Mendel (1995).

Fuzzy Logic Example. At least once a day consumers find themselves having to choose a queue to get into. What is the decision making process a person goes through to pick the correct line for their needs? Consumers could look at:

1. Length of line

2. Average number of items other consumers have in line

3. Human or Automated checker

4. Whether there is a need to get through the line quickly.

A Fuzzy Logic system could be created using the criteria above as the Fuzzy Sets and creating membership functions for each. The Membership Functions are listed below in Table 2. Length of line would be a Fuzzy Set with "Empty" being 10 and "Really Long" being 0 . 


\begin{tabular}{|c|c|c|c|c|}
\hline $\begin{array}{c}\text { Length of } \\
\text { Line }\end{array}$ & $\begin{array}{c}\text { Average } \\
\text { Number of } \\
\text { Items }\end{array}$ & Checker & Need to Leave & Result \\
\hline Empty & Less than 10 & Human & No Rush & Pick line \\
\hline Short & Around 20 & Automated & Impatient & Don't pick line \\
\hline Average & Around 40 & & Emergency & \multirow{2}{*}{} \\
\cline { 1 - 2 } Long & More than 60 & & & \\
\hline Really Long & & & \\
\hline
\end{tabular}

Now membership functions would be created for all five Fuzzy Sets. The membership function for "length of line" is given below in Figure 9.

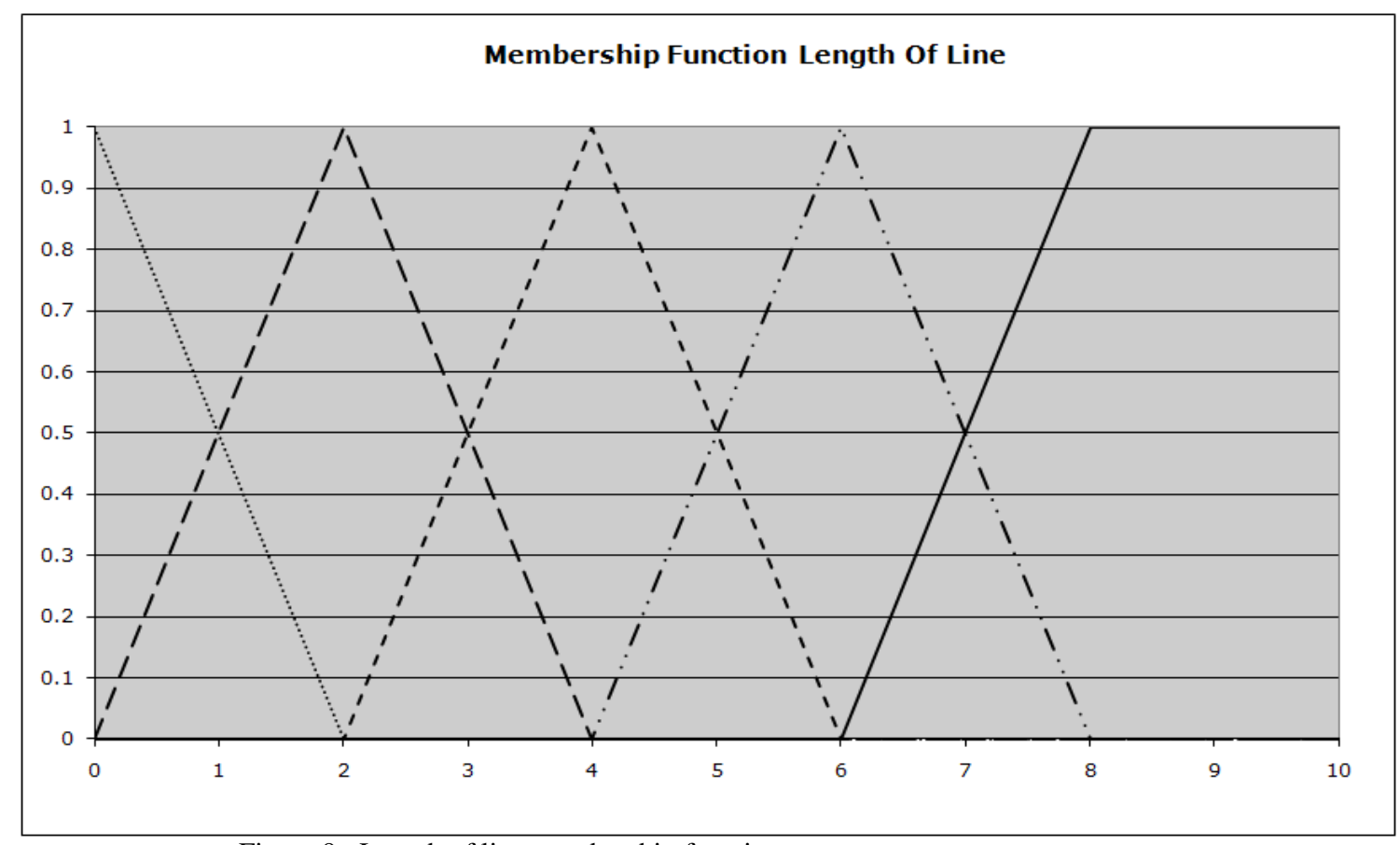

Figure 9: Length of line membership function

Example of rules:

1. IF "Length of line" is Empty AND "Num. of Items" is Less than 10 AND

"Checker" is Human AND "Need to leave" is No Rush THEN Pick Line.

2. IF "Length of line" is Really Long AND "Num. of Item"s is Around 40

AND "Checker" is Automated AND "Need to leave" is Emergency THEN

Do Not Pick Line. 
When all the rules have been created, the membership functions defined and all information validated / verified the user can start using the Fuzzy Logic system. In this system the consumer would walk up to the checkout lines in any store and observe what was happening around him / her. Once all necessary information was gathered, the consumer would put his or hers inputs into the Fuzzy Logic system. Example:

1. Length of line $=8$ people

2. Ave. num. of items / customer $=25$

3. Checker $=1$ (Human)

4. Need to leave $=9$

When the input data is placed into MATLAB the user would receive an output of a crisp number equaling $=2.7$ based on a scale of 0 to 10 . This number represents a figure of merit which the consumer could use to determine which line to enter. After determining the figure of merit for all lines, the consumer should choose the line with the highest value. This assumes that the consumer does not have the choice of leaving without purchase. See Appendix A for a sample of Membership Function intersections.

\section{Applications of Fuzzy Logic}

Fuzzy Logic systems can be applied to many situations or decisions because Fuzzy Logic systems seem to work similar to our brains. Fuzzy Logic research may lead to the development of much smarter, more "human-like" computers.

Maiers and Sherif (1985) and Tizhoosh (2004) list fuzzy logic applications areas in their research. Table 3 lists a few applications.

Combination of Fuzzy Logic and Neural Nets Matsushita 


\begin{tabular}{|l|l|}
\hline Medicine technology: cancer diagnosis & Kawasaki Medical School \\
\hline $\begin{array}{l}\text { Prediction system for early recognition of } \\
\text { earthquakes }\end{array}$ & $\begin{array}{l}\text { Inst. of Seismology Bureau of } \\
\text { Metrology, Japan }\end{array}$ \\
\hline Archiving system for documents & Mitsubishi Electric \\
\hline Optimized planning of bus time-tables & $\begin{array}{l}\text { Toshiba, Nippon-System, Keihan- } \\
\text { Express }\end{array}$ \\
\hline $\begin{array}{l}\text { Positioning of wafer-steppers in the production } \\
\text { of semiconductors }\end{array}$ & Canon \\
\hline $\begin{array}{l}\text { Cruise-control for automobiles } \\
\text { Preventing unwanted temperature fluctuations } \\
\text { in air-conditioning systems }\end{array}$ & Nissan, Subaru \\
\hline $\begin{array}{l}\text { Automatic control of dam gates for } \\
\text { hydroelectric-power plants }\end{array}$ & Tokio Electric Power \\
\hline $\begin{array}{l}\text { Improved sensitiveness and efficiency for } \\
\text { elevator control }\end{array}$ & Fujitec, Hitachi, Toshiba \\
\hline Table 3: Partial list of Fuzzy Logic real world applications (http://pami.uwaterloo.ca/tizhoosh/Turotial2.htm)
\end{tabular}

\section{Personality Traits of Salespersons}

The analysis of criteria for the evaluation of personality traits of employees in a sales industry has been researched extensively. Nationwide studies come out every year discussing what traits the top sales individuals have. The research performed pinpoints important criteria of top sales individuals. Identifying the traits of top sales people allows managers to rank their employees against these researched traits. These initial rankings will be used to calculate an employee's ability to sell merchandise to different customer groups.

Researchers at the University of Florida (Ruth and Wysocki, 2008) give three common sets of attributes for a superior salesperson: 
1. "The first set of common attributes come from Harvard Business School.
a. Highly successful salespeople do not take "NO" personally
b. Takes $100 \%$ responsibility for results
c. Possess empathy
d. Above average ambition, empathy, willpower and determination
e. Intensely goal-oriented
f. Can easily approach strangers

2. The second set of common attributes was identified by Drs. Jeanne and Herbert Greenberg.

a. Salesperson needs three basic traits to be successful: empathy, ego drive, and ego strength.

3. A third set of common attributes are listed in an article by Sardar and Patton.
a. Job commitment
h. Persistence
b. Strategic orientation
i. Courage
c. Intellect
j. Ability to improvise
d. Mental alertness
k. Inquisitiveness
e. Sociability
1. Forcefulness
f. Authoritative
m. Tenacity
g. Dependability
n. Straightforwardness"

In 2005 Kelly Robertson, President of the Robertson Training Group (http://www.businessknowhow.com/marketing/successful-salesperson.htm), who works with businesses to help increase sales and motivate their employees, published a list of 
characteristics of successful salespeople. The list published in Robertson's research contains ten different characteristics which are similar to Ruth and Wysocki's. The characteristics are:
1. Persistent
6. Enthusiastic
2. Avid goal setters
7. Take responsibility for their results
3. Ask quality questions
8. Work hard
4. Listen
9. In touch with their clients
5. Passionate
10. Show value

There are certain sales characteristics that appear in all the studies and were thought to be more important than others. The overlapping characteristics will be the ones used in this research. A list of these sales characteristics is in Chapter IV: Proposed Methodology. 


\section{CHAPTER III}

\section{THE PROPOSED METHODOLOGY}

Managers look for hundreds of qualities in employees' personalities, work ethics, history, attitude, and etc. Managers rely on personal experiences to be able to accomplish this complicated task. The steps a manager goes through could be modeled in a Fuzzy Logic system. However, organizing all the data into a Fuzzy Logic System (FLS) can be a daunting task.

This thesis proposes a Fuzzy Logic System for the creation of a scheduling methodology that maximizes estimated sales. Figure 10 is a high level pictorial representation of how a Fuzzy Logic System and Linear Programming will be used in this methodology. As discussed previously, once a list of sales criteria is developed through a literature review, a Fuzzy Logic System is set up. The FLS will include Fuzzy Sets, Membership Functions and If / Then Rules. The Fuzzy Sets are split into two categories: Sales Characteristics and Customer Type. The six different Sales Characteristics Fuzzy Sets were agreed to by experts within the field and developed through the Literature Review. Employee characteristics were analyzed to determine the shapes of the membership functions and then reviewed with multiple experts to insure accuracy. This was done to generate an accurate and reliable structure of the fuzzy system. Finally, the Linear

Program was developed to incorporate the output from the Fuzzy Logic System to optimize the Estimated Sales based on simplified constraints. 


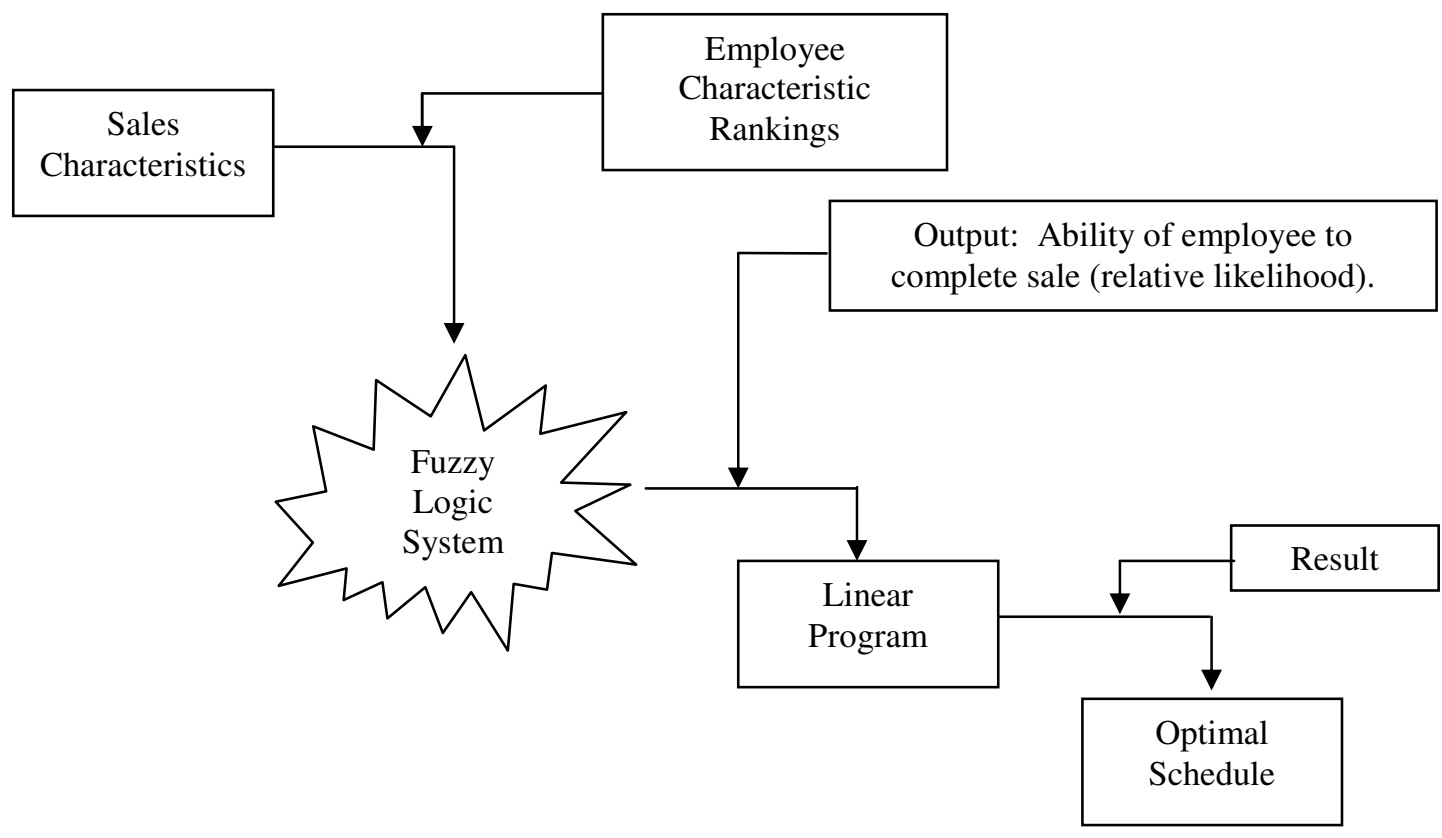

Figure 10: New methodology flow diagram

Figure 11 breaks down the Fuzzy Logic System and the Linear Program in depth. It pictorially shows how the output of the FLS is used in the Linear Program. The FLS is used to provide the LP a crisp output that represents the sales employee ability to complete a sale given a certain type of customer. Once the LP has the output from the FLS, the FLS uses it to calculate the estimated sales for a defined time period given certain customer types. The objective function then maximizes the estimated sales, producing a schedule. 

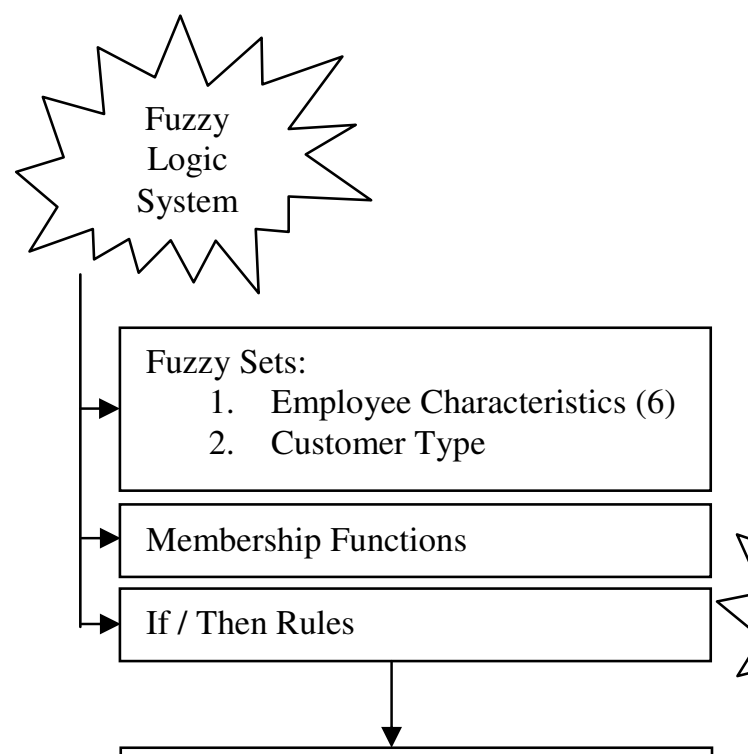

Output: Employees ability to complete a sale per customer type.

Figure 11: FLS and LP flow diagram

Using the Fuzzy Logic toolbox in MATLAB, the Fuzzy Sets were generated by collecting expert data to create membership functions and If / Then rules. Therefore, management does not have to choose the parameters associated with a given membership function arbitrarily. At the first stage, specific performance criteria are identified and appropriate Fuzzy Sets are created with membership functions. Subsequently If / Then rules are formed using experts. All this information is placed into MATLAB's Fuzzy Logic Toolbox, which will give a crisp output to be used in an Excel based tool that takes FLS's output as as inputs into the Linear Program. Data describing the hourly shifts, 
impacted times and number of employees will be inputted to this tool to create a schedule that will maximize estimated sales.

\section{Performance Criteria and Data Collection}

The proposed methodology gives the responsibility to individual managers to determine the suitable performance criteria for their business environment. The literature review discusses criteria that top sales people have. Every industry has their own specific performance criteria and characteristics needed in employees and from company to company in a specific industry these can vary tremendously. Yet, some fundamental criteria are always needed in a sales environment. The following list is the most valuable and applicable across a board spectrum of business types.

1. Energetic

2. Trustworthy

3. Experience in that business

4. Integrity

5. Self discipline

6. Motivation
8. Personality

9. Self-confidence

10. Hunger for money

11. Communication

12. Believability

13. Commitment.

\section{Product knowledge}

Criteria needs to be developed to describe characteristics of customers. Discussions with experts have lead to dividing customers into three categories:

1. Lookie Lous

2. Price Shoppers

3. Buyers 
Lookie Lous are the type of customer that have no intention of buying, but are out to see what people are offering. They test the waters and see which company fits their needs and personalities the best. Price shoppers have already looked around, and know what they want, but they are not sure where they want to get it. They are looking for the best

deal in town. A good sales employee needs to be able to entice this type of customer to buy. The last type of customer is the Buyers. These individuals have done their research, looked around, saw who had the best deals and are now ready to purchase.

The input-output data from past performance of employees, and the relative likelihood of selling a product based on the type of customer, will then be used to generate the structure of the fuzzy system. The next crucial step is taking the employee characteristics, and breaking down each category into a Fuzzy Set. This will allow membership functions to be created later.

\section{Setting Up MATLAB}

After careful consideration of criteria, the Fuzzy Sets are developed with help from experts and research. The finalized list has been shortened because of the different possibilities. If all thirteen criteria were used, and 5, or even 3 variables were in each set, the total number of options would be enormous. The equation to calculate the total number of rules is

$$
\text { (Linguistic Variables }{ }^{\text {Fuzzy Sets }} \text { ) * Number of Customer Types }
$$


Table 4 shows how the number of rules decreases dramatically by reducing the number of Fuzzy Sets and variables.

\begin{tabular}{|c|c|c|c|}
\hline $\begin{array}{c}\text { Fuzzy } \\
\text { Sets }\end{array}$ & $\begin{array}{c}\text { Linguistic } \\
\text { Variables }\end{array}$ & $\begin{array}{c}\text { Number of } \\
\text { Customer Types }\end{array}$ & $\begin{array}{c}\text { Total Number of } \\
\text { Rules }\end{array}$ \\
\hline 13 & 5 & 3 & $3,662,109,375$ \\
\hline 13 & 3 & 3 & $4,782,969$ \\
\hline 6 & 5 & 3 & 46,875 \\
\hline 6 & 3 & 3 & 2,187 \\
\hline
\end{tabular}

Table 4: Number of rules based on Fuzzy Sets and variables

With the number of rules becoming unrealistic as the Fuzzy Sets and variables increase this thesis will utilize 7 Fuzzy Sets (Energy level, Experience in that business, Personality, Self-confidence, Communication skills, Commitment and Customer type) and 3 linguistic variables (Low, Average, High). The number of Fuzzy Sets can be decreased based on a ranking system of most important characteristics to least. Experts in the sale industry were asked to rank each of the thirteen criteria. Only the top six were kept. In total, five experts were asked. The experts were chosen based on experience level and sales industry. For a better representation of sales characteristics a wide range of industries were used. The industries included, but were not limited to automobile sales, electronics, and local wine bar. A list of the final seven Fuzzy Sets and linguistic variables is provided in Table 5 . 


\begin{tabular}{|c|c|c|c|c|c|c|}
\hline $\begin{array}{c}\text { Energy } \\
\text { Level }\end{array}$ & Experience & Personality & $\begin{array}{c}\text { Self- } \\
\text { Confidence }\end{array}$ & $\begin{array}{c}\text { Communication } \\
\text { Skills }\end{array}$ & Commitment & Customer \\
\hline Low & None & None & None & None & None & $\begin{array}{c}\text { Lookie- } \\
\text { Lou }\end{array}$ \\
\hline Average & Average & Average & Average & Average & Average & $\begin{array}{c}\text { Price } \\
\text { Shopper }\end{array}$ \\
\hline High & Expert & Great & High & High & High & Buyer \\
\hline
\end{tabular}

Table 5: List of six Fuzzy Sets and customer types

Since the Fuzzy Sets have been finalized, the membership functions can be developed to represent the linguistic variables. Membership functions have been created to represent the top characteristics of the sale people and the different types of customers. To generate these functions, lengthy conversations were held with different sales experts to decide on the correct curvature of the function. Each membership function has a y-axis between 0 and 1 depending on the degree of membership and an x-axis between 0 and 10 . Shown in Figure 12 is an example of one of the membership functions used in this methodology.

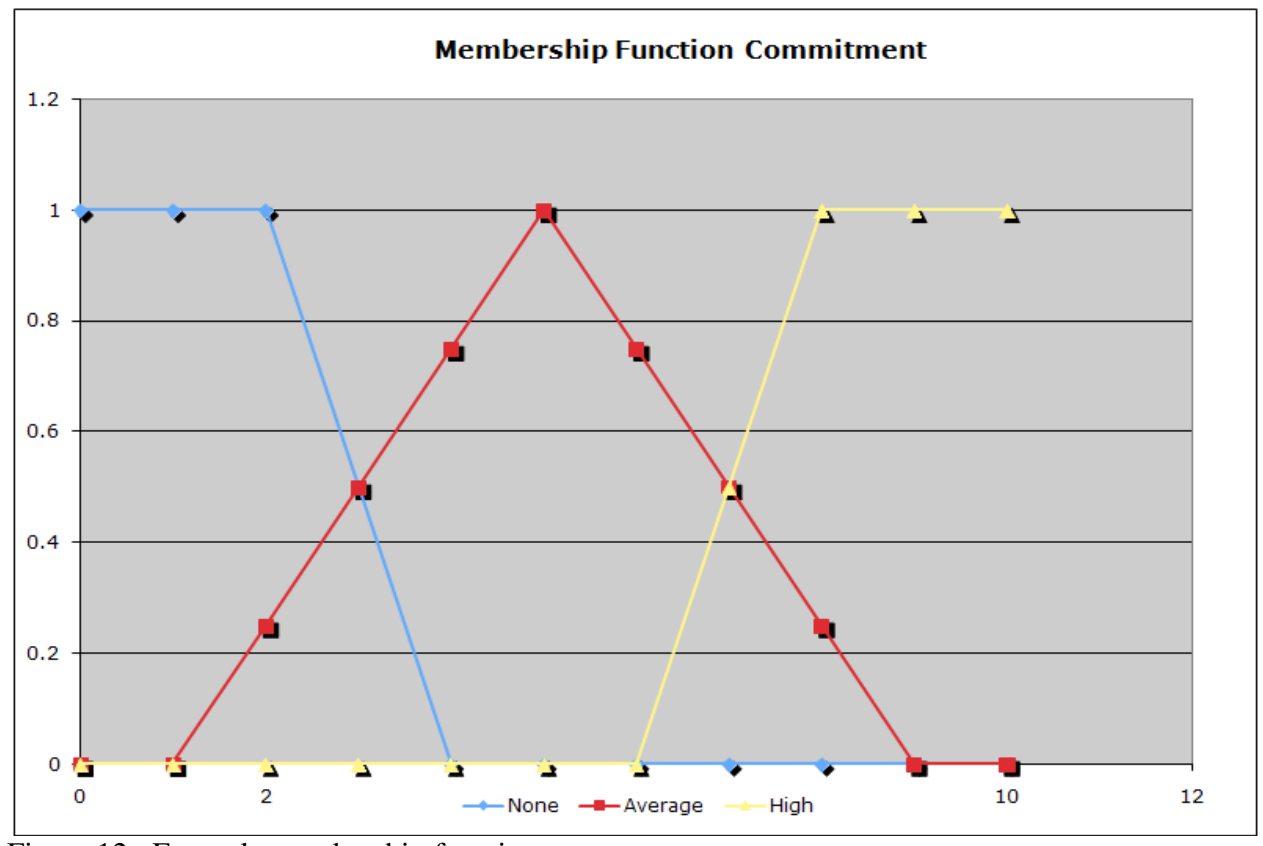

Figure 12: Example membership function 
The figure above shows the three different curves that represent the linguistic variables. Notice how the three curves overlap to account for differences in opinion of where one should stop and another start. This membership function is a good graphical representation of how breaking down one sales characteristic is impossible with classical sets and why Fuzzy Logic is needed. In total, seven membership functions were generated to represent all seven Fuzzy Sets. The membership functions can be seen in the Appendix.

If / Then rules have to be developed so that MATLAB can calculate a crisp output. Experiences of experts have been used to help in the creation of the If / Then rules to ensure accuracy. As shown in Table 4, there are 2,187 rules in the developed FLS. An example of three rules would be

1. If Energy (Level is Low) and (Experience is None) and (Personality is None) and (Self-Confidnece is None) and (Communication is None) and (Commitment is None) and (Customer is Lookie-Lou) then (Product is Not Sold).

2. If Energy (Level is Average) and (Experience is Average) and (Personality is Average) and (Self-Confidnece is Average) and (Communication is Average) and (Commitment is Average) and (Customer is Price Shoppers) then (Product is Not Sold).

3. If Energy (Level is High) and (Experience is Expert) and (Personality is Great) and (Self-Confidence is High) and (Communication is High) and (Commitment is High) and (Customer is Buyer) then (Product is Sold). 
With all the MATLAB inputs set, verifying and validating the output given certain inputs is essential to ensure that the membership functions and rules were created correctly. The Fuzzy Logic system can be verified through various editing screens in MATLAB.

\section{Validation and Verification}

Verification and validation of the resulting fuzzy inference system can be performed in a few ways. Verification can happen through the rule editor and the rule viewer pages in MATLAB. This screen is going to be critical in obtaining the correct output because adjustments to the Fuzzy Sets can be made quickly to produce the correct output. If the membership functions need to be adjusted, they can be adapted from their initial settings with a few clicks of the mouse. The second confirmation is in the rule viewer screen. This area is an easy and accurate way to check the rules and membership functions all at once.

The most valuable and accurate validation method is through experts. When the fuzzy inference system is completed and output is starting to be generated expert review is crucial to the accuracy of the system. The FLS was validated by the same experts that helped design the Fuzzy Sets and Membership Functions. This system was difficult to validate because of the 2,187 rules that were generated. Each rule was scrutinized to ensure correctness. Before the experts agreed to the results, a few iterations were tested. Once the Fuzzy Logic System was producing a crisp output that the experts agreed too, a Linear Program could be developed. The next section will break down a simplified Linear Program that incorporates the FLS output. 


\section{Linear Programming Formulation}

The Linear Program formulation can be seen below. It has been broken up into multiple sections.

Assumptions. To simplify the Linear Program some basic assumptions were made.

1. Distribution of customers is the same every week

2. Every employee has the same salary

3. Employees do not get holidays off

4. All employees work 35 hours a week

5. Employees will not work more than seven (7) straight hours

6. A minimum of 1 employee is scheduled for every shift

\section{Definition of Terms.}

Customer Type - CT

1. LL - Lookie Lou

2. PS - Price Shopper

3. B-Buyer

Day of week - k
1. Sunday
5. Thursday
2. Monday
6. Friday
3. Tuesday
7. Saturday
4. Wednesday 
Shifts - j

1. $8-11$

2. $11-3$

3. $3-6$

4. $6-10$

Employee - i

1. Employee 1

2. Employee 2

3. Employee 3

4. Employee 4

5. Employee 5

Constants. The constants below are supplied to the Linear Program. They could be derived from time studies, questionnaires, simulations, surveys and historical data. $\mathrm{ES}_{\mathrm{iw}}$ - Estimated Sales of employee i during shift/day w $A_{i L L}$ - Likelihood for employee i to sell to Lookie Lou (From FLS) $A_{i P S}$ - Likelihood for employee i to sell to Price Shopper (From FLS) $A_{i B}$ - Likelihood for employee i to sell to Buyer (From FLS) $\mathrm{P}_{\mathrm{LLw}}$ - Percent Lookie Lou during shift/day w $\mathrm{P}_{\mathrm{PSw}}-$ Percent Price Shopper during shift/day w $\mathrm{P}_{\mathrm{Bw}}-$ Percent Buyer during shift/day w $D_{w}-$ Known number of workers required on Shift/Day w $(w=1, \ldots, 28)$ $\mathrm{J}_{\mathrm{w}}=$ Number of hours worked during shift $\mathrm{w}$ w - Shift/Day 
$\mathrm{N}_{\mathrm{w}}-$ Number of Customers during shift/day w

Variable. The variables used are define as follows.

$\mathrm{X}_{\mathrm{iw}}=1$ if employee $\mathrm{i}$ is assigned to start on Shift $\mathrm{w}$ and 0 otherwise, where $\mathrm{i}=1,2,3,4,5$

and $\mathrm{w}=1, \ldots, 28$ 
Spreadsheet. A spreadsheet was created to help organize the data collected from experts. The data contained in the spreadsheet are considered constants in the Linear Program formulation. This information would have to be determined before the LP is run.

\begin{tabular}{|c|c|c|c|c|}
\hline w & $\begin{array}{l}\text { Weekday } \\
(\mathrm{k})\end{array}$ & $\begin{array}{l}\text { Shift } \\
\text { (j) }\end{array}$ & $\begin{array}{l}\text { Estimated } \\
\% \text { of CT }\end{array}$ & $\begin{array}{c}\text { \# of } \\
\text { Employees } \\
\text { Required }\end{array}$ \\
\hline \multirow{3}{*}{1} & \multirow{3}{*}{ Monday } & \multirow{3}{*}{$8-11$} & $\mathrm{LL}$ & \\
\hline & & & PS & \\
\hline & & & $\mathrm{B}$ & \\
\hline \multirow{3}{*}{2} & \multirow{3}{*}{ Monday } & \multirow{3}{*}{$11-3$} & LL & \\
\hline & & & PS & \\
\hline & & & $\mathrm{B}$ & \\
\hline \multirow{3}{*}{3} & \multirow{3}{*}{ Monday } & \multirow{3}{*}{$3-6$} & LL & \\
\hline & & & PS & \\
\hline & & & $\mathrm{B}$ & \\
\hline \multirow{3}{*}{4} & \multirow{3}{*}{ Monday } & \multirow{3}{*}{$6-10$} & LL & \\
\hline & & & PS & \\
\hline & & & $\mathrm{B}$ & \\
\hline \multirow{3}{*}{5} & \multirow{3}{*}{ Tuesday } & \multirow{3}{*}{$8-11$} & LL & \\
\hline & & & PS & \\
\hline & & & $\mathrm{B}$ & \\
\hline \multirow{3}{*}{6} & \multirow{3}{*}{ Tuesday } & \multirow{3}{*}{$11-3$} & LL & \\
\hline & & & PS & \\
\hline & & & $\mathrm{B}$ & \\
\hline \multirow{3}{*}{7} & \multirow{3}{*}{ Tuesday } & \multirow{3}{*}{$3-6$} & LL & \\
\hline & & & PS & \\
\hline & & & $\mathrm{B}$ & \\
\hline \multirow{3}{*}{8} & \multirow{3}{*}{ Tuesday } & \multirow{3}{*}{$6-10$} & LL & \\
\hline & & & PS & \\
\hline & & & $\mathrm{B}$ & \\
\hline & & & LL & \\
\hline 9 & Wednesday & $8-11$ & PS & \\
\hline & & & $\mathrm{B}$ & \\
\hline & & & $\mathrm{LL}$ & \\
\hline 10 & Wednesday & $11-3$ & PS & \\
\hline & & & $\mathrm{B}$ & \\
\hline & & & LL & \\
\hline 11 & Wednesday & $3-6$ & PS & \\
\hline & & & $\mathrm{B}$ & \\
\hline & & & LL & \\
\hline 12 & Wednesday & $6-10$ & PS & \\
\hline & & & $\mathrm{B}$ & \\
\hline & & & $\mathrm{LL}$ & \\
\hline 13 & Thursday & $8-11$ & PS & \\
\hline & & & $\mathrm{B}$ & \\
\hline & & & LL & \\
\hline 14 & Thursday & $11-3$ & PS & \\
\hline & & & $\mathrm{B}$ & \\
\hline
\end{tabular}

\begin{tabular}{|c|c|c|c|c|}
\hline $\mathrm{w}$ & $\begin{array}{c}\text { Weekday } \\
(\mathrm{k})\end{array}$ & $\begin{array}{l}\text { Shift } \\
\text { (j) }\end{array}$ & $\begin{array}{c}\text { Estimated } \\
\% \text { of CT }\end{array}$ & $\begin{array}{c}\text { \# of } \\
\text { Employees } \\
\text { Required }\end{array}$ \\
\hline \multirow{3}{*}{15} & \multirow{3}{*}{ Thursday } & \multirow{3}{*}{$3-6$} & $\mathrm{LL}$ & \\
\hline & & & PS & \\
\hline & & & B & \\
\hline \multirow{3}{*}{16} & \multirow{3}{*}{ Thursday } & \multirow{3}{*}{$6-10$} & LL & \\
\hline & & & PS & \\
\hline & & & $\mathrm{B}$ & \\
\hline \multirow{3}{*}{17} & \multirow{3}{*}{ Friday } & \multirow{3}{*}{$8-11$} & LL & \\
\hline & & & PS & \\
\hline & & & $\mathrm{B}$ & \\
\hline \multirow{3}{*}{18} & \multirow{3}{*}{ Friday } & \multirow{3}{*}{$11-3$} & LL & \\
\hline & & & PS & \\
\hline & & & $\mathrm{B}$ & \\
\hline \multirow{3}{*}{19} & \multirow{3}{*}{ Friday } & \multirow{3}{*}{$3-6$} & LL & \\
\hline & & & PS & \\
\hline & & & $\mathrm{B}$ & \\
\hline \multirow{3}{*}{20} & \multirow{3}{*}{ Friday } & \multirow{3}{*}{$6-10$} & $\mathrm{LL}$ & \\
\hline & & & PS & \\
\hline & & & $\mathrm{B}$ & \\
\hline \multirow{3}{*}{21} & \multirow{3}{*}{ Saturday } & \multirow{3}{*}{$8-11$} & LL & \\
\hline & & & PS & \\
\hline & & & $\mathrm{B}$ & \\
\hline \multirow{3}{*}{22} & \multirow{3}{*}{ Saturday } & \multirow{3}{*}{$11-3$} & LL & \\
\hline & & & PS & \\
\hline & & & $\mathrm{B}$ & \\
\hline & & & LL & \\
\hline 23 & Saturday & $3-6$ & PS & \\
\hline & & & $\mathrm{B}$ & \\
\hline & & & LL & \\
\hline 24 & Saturday & $6-10$ & PS & \\
\hline & & & $\mathrm{B}$ & \\
\hline & & & $\mathrm{LL}$ & \\
\hline 25 & Sunday & $8-11$ & PS & \\
\hline & & & $\mathrm{B}$ & \\
\hline & & & LL & \\
\hline 26 & Sunday & $11-3$ & PS & \\
\hline & & & $\mathrm{B}$ & \\
\hline & & & LL & \\
\hline 27 & Sunday & $3-6$ & PS & \\
\hline & & & $\mathrm{B}$ & \\
\hline & & & $\mathrm{LL}$ & \\
\hline 28 & Sunday & $6-10$ & PS & \\
\hline & & & $\mathrm{B}$ & \\
\hline
\end{tabular}

Table 6: Employee worksheet 
Formulation. The Linear Programming Formulation only uses the necessary basic information to run the model. A more complex environment can easily be represented by creating more variables and constraints. The LP formulation in this thesis is only meant to serve as an example of the capabilities within this new methodology.

\section{Objective Function.}

$$
\begin{gathered}
\operatorname{Max} \mathrm{Z}=\sum(\mathrm{w}=1-3,5-7,9-11,13-15,17-19,21-23,25-27) \mathrm{ES}_{\mathrm{iw}} * \mathrm{X}_{\mathrm{iw}}+\mathrm{ES}_{\mathrm{iw}+1} * \mathrm{X}_{\mathrm{iw}}(\mathrm{i}=1, \ldots, 5) \\
* \mathrm{X}_{\mathrm{i}-4}, \mathrm{X}_{\mathrm{i}-8}, \mathrm{X}_{\mathrm{i}-12}, \mathrm{X}_{\mathrm{i}-16}, \mathrm{X}_{\mathrm{i}-20}, \mathrm{X}_{\mathrm{i}-24} \text { and } \mathrm{X}_{\mathrm{i}-28} \text { are not used because a } \\
\text { salesperson can't start their shift on the fourth shift of the day. }
\end{gathered}
$$

\section{Constants.}

Estimated Sales:

$$
\mathrm{ES}_{\mathrm{iw}}=\left(\left(\mathrm{A}_{\mathrm{iLL}} * \mathrm{P}_{\mathrm{LLW}}\right)+\left(\mathrm{A}_{\mathrm{iPS}} * \mathrm{P}_{\mathrm{PSW}}\right)+\left(\mathrm{A}_{\mathrm{iB}} * \mathrm{P}_{\mathrm{Bw}}\right)\right) * \mathrm{~N}_{\mathrm{w}}
$$

\section{Constraints.}

Max number of days worked:

$\sum(\mathrm{w}=1$ to 28$) \mathrm{X}_{\mathrm{iw}} \leq 5$ for $\mathrm{i}=1, \ldots, 5$

Force employees to work 2 consecutive shifts:

$$
\begin{aligned}
& X_{i 1}+X_{i 2}+X_{i 3} \leq 1 \text { for } i=1, \ldots, 5 \\
& X_{i 5}+X_{i 6}+X_{i 7} \leq 1 \text { for } i=1, \ldots, 5 \\
& X_{i 9}+X_{i 10}+X_{i 11} \leq 1 \text { for } i=1, \ldots, 5 \\
& X_{i 13}+X_{i 14}+X_{i 15} \leq 1 \text { for } i=1, \ldots, 5 \\
& X_{i 17}+X_{i 18}+X_{i 19} \leq 1 \text { for } i=1, \ldots, 5 \\
& X_{i 21}+X_{i 22}+X_{i 23} \leq 1 \text { for } i=1, \ldots, 5 \\
& X_{i 25}+X_{i 26}+X_{i 27} \leq 1 \text { for } i=1, \ldots, 5
\end{aligned}
$$

Minimum number of employees per shift:

Working shift 1 (Starting shift 1) 
$\sum(\mathrm{i}=1$ to 5$) \mathrm{X}_{\mathrm{iw}} \geq \mathrm{D}_{\mathrm{w}}$ for $\mathrm{w}=1,5,9,13,17,21,25$

Working shift $1 \& 2$ (Ending shift 2)

$\sum(\mathrm{i}=1$ to 5$) \mathrm{X}_{\mathrm{iw}-1}+\mathrm{X}_{\mathrm{iw}} \geq \mathrm{D}_{\mathrm{w}}$ for $\mathrm{w}=2,6,10,14,18,22,26$

Working shift $2 \& 3$ (Starting shift 2)

$\sum\left(\mathrm{i}=1\right.$ to 5) $\mathrm{X}_{\mathrm{iw}-1}+\mathrm{X}_{\mathrm{iw}} \geq \mathrm{D}_{\mathrm{w}}$ for $\mathrm{w}=3,7,11,15,19,23,27$

Working shift $3 \& 4$ (Starting shift 3 )

$\sum\left(\mathrm{i}=1\right.$ to 5) $\mathrm{X}_{\mathrm{iw}} \geq \mathrm{D}_{\mathrm{w}+1}$ for $\mathrm{w}=3,7,11,15,19,23,27$

The next chapter will validate and verify the proposed methodology through a case study. 


\section{CHAPTER IV}

\section{CASE STUDY \& RESULTS}

To validate this new methodology, a case study was performed. The owner of Sunset Honda in San Luis Obispo, Don Woodward, has allowed this methodology to be validated on his car dealership. Sunset Honda is a perfect example of the type of business that can be impacted positively by this methodology. Sunset Honda like any other retail business has its success based on the ability of the sales department to turn over inventory. Only the Fuzzy Logic System was validated at Sunset Honda. The Linear Program is only an example of how a Fuzzy Logic System's output can be used in a Linear Program.

\section{Sunset Honda}

After collecting all the initial data on each employee, Mr. Woodward reviewed the findings and made any adjustments needed based on his 25 plus years experience. After the Fuzzy Logic inputs had been finalized Mr. Woodward sat down with one of his managers and reviewed each employee's rating in the sales department on each of the six Fuzzy Sets listed previously. Mr. Woodward and his managers rated each employee on a scale from 1 to 10. All the required information had been obtained for the Fuzzy Logic System. Mr. Woodward also had the opportunity to make any changes to the membership functions to achieve the correct "Likelihood of Sales" before the program was ran. An excerpt of the Relative Likelihood of Sales Chart can be seen in the Appendices. 
An example of one sales employee would be:

1. Energy Level $=\quad 8$

2. Experience $=2$

3. Personality $=9$

4. Self-Confidence $=\quad 9$

5. Communications $=6$

6. Commitment $=\quad 5$

Based on these scores, this sales employee would have the below relative likelihood of completing a sale to the three customer types.

1. Lookie Lou $=$ $22.6 \%$

2. Price Shopper $=$ $49.5 \%$

3. Buyer $=$ $74.9 \%$

Results. After inputting all the data collected from Mr. Woodward, the Fuzzy Logic output could be analyzed. Mr. Woodward explained that the output from the FLS was unexpected of what he knew of his sales department. Mr. Woodward went on further to explain that he put too much emphasis on previous sales experience and ignored other factors. Mr. Woodward than took the output and used it to reschedule the department based on his knowledge of the customer demand. Sunset Honda did see a small increase in sales over a month period. A Linear Program was never specifically created for Sunset Honda, but a basic Linear Program was created to show how a FLS could be used as an input. Using the FLS from Sunset Honda, and the basic LP, an optimal solution was found using Microsoft's Excel Solver. 


\section{Adaptability to other businesses}

This methodology may be adaptable to many sales environments. The fuzzy Logic inputs, membership functions, If / Then rules can be changed depending on the business. The Linear Program can be simple or as complex as needed to properly simulate the business' schedule requirements. 


\section{CHAPTER V}

\section{CONCLUSION AND FURTHER STUDY}

Throughout this document there has been one goal to combine Industrial Engineering concepts. The methodology presented in this thesis explored and combined two such concepts: Fuzzy Logic and Linear Programming. These two disciplines have rarely come together to work as one. The combination of these has produced an extremely powerful scheduling optimization tool that is adaptable to any situation/industry. Virtually any business where customer demand varies could use this methodology to solve their scheduling needs: restaurants, electronic stores, car dealerships. The Fuzzy Logic System accurately represented Sunset Honda's sales department and its ability to sell goods. The Linear Program was able to incorporate the output from the Fuzzy Logic System to optimize the Estimated Sales based on simplified constraints. The case study results were reviewed by industry experts and each agreed they results accurately represented Sunset Honda's sale department. The methodology implemented for Sunset Honda was a success and only the beginning.

This work can be further developed in the following areas:

1. Expand the Linear Program to be identical to the business. The LP used in this methodology was a simple example. A realistic LP should be used to represent the scheduling problem.

2. Workforce requirements are always assumed a given which simplifies the problem. In the "real word," this assumption may be relaxed. Linear Programming could incorporate the uncertainty of unknown requirements. 
3. Use a description of the work to be done rather than the number of workers required. The present research can be extended to include the calculation of the number and types of workers needed based on work tasks and their content.

4. Since employees can substitute for each other causing less qualified employees to be present at inappropriate times, create the Linear Program to handle sick leave, vacations, holidays, and etc. 


\section{REFERENCES}

1993 UG Exam, Linear Programming example. Retrieved May 30, 2011, from http://people.brunel.ac.uk/ mastjjb/jeb/or/lpmore.html

Balakrishnan, N., Render, B., \& Stair, R. (2006). Managerial Decision Modeling $2^{\text {nd }}$ Edition, Prentice Hall, Englewood Cliffs, NJ.

Barron, J., "Putting Fuzzy Logic into Focus," Byte, April 1993, p. 11 1- 118.

Begg, R \& Marimuthu, P. (2006). Computational Intelligence for Movement Sciences, Idea Group Publishing, Hershy, PA.

Braae, M. \& Rutherford, D.A. (1979). Theoretical and linguistic aspects of the fuzzy logic controller, Automatic, vol. 15, pp. 553-577

Cox, E., "Adaptive Fuzzy Systems," IEEE Spectrum, February 1993, p. 27-31.

Diao, Y., (2002). Using fuzzy control to maximize profits in service level management. IBM Systems Journal, Vol 41, No 3.

Greenberg, H.M., \& Greenberg, J. (1983). The personality of a top salesperson: Nations Business. Retrieved February 6, 2002 from the Internet. Web site: http://www.calipercanada.com/personality.htm

Hillier, F. \& Lieberman, G. (2009). Introduction to Operations Research $9^{\text {th }}$ Edition, McGraw-Hill Science/Engineering/Match, Columbus OH.

Jang, J., (1993). ANFIS: Adaptive-Network-Based Fuzzy Inference System. IEEE Trans. on Systems, Man and Cybernetics, vol. 23, no. 3, pp. 665-685,May 1993

Karmarkar, N. (1984). Linear Programming Retrieved May 2, 2011, from http://cs.nyu.edu/faculty/overton/g22_lp/encyc/article_web.html

Karnik, N. \& Mendel, J. (1998). Type-2 Fuzzy Logic Systems: Type-Reduction, presented at IEEE Syst., Man, Cybern. Conf., San Diego, CA, Oct. 1998.

Karnik, N. \& Mendel, J. (1999). Type-2 Fuzzy Logic Systems, IEEE Transactions on Fuzzy Systems. Vol7, No. 6.

Kecman, V., (2001). Learning and Soft Computing: support vector machines, neural networks, and fuzzy logic models. Massachusetts Institue of Technology

Klein, \& Langholz, (1998). Systems, Man and Cybernetics. IEEE, Oct 1998, 445-450 
Kosko, B. (1992). Neural Networks and Fuzzy Systems: A Dynamical Systems Approach to Machine Intelligence, Prentice Hall, Englewood Cliffs, NJ.

Maiers, J. and Sherif, Y. S. (1985) Applications of fuzzy set theory, IEEE Transactions on Systems, Man and Cybernetics, 15(1), 175-189.

Mamdani, E. H. and Assilian, S., "An Experiment in Linguistic Synthesis with a Fuzzy Logic Controller," International Journal of Man Machine Studies, Vol. 7, 1975, p $1-13$.

Mathworks. (2010). Fuzzy Logic Toolbox ${ }^{\mathrm{TM}}$ 2, User's Guide. Retrieved from www.mathworks.com

Megiddo, N. \& Dyer, M. (1997). Linear programming in low dimensions. Discrete \& computational geometry - DCG.

Mendel, J., (1995). Fuzzy logic systems for engineering: a tutorial, IEEE Proc., vol. 83, no. 3,pp. 345-377.

Mendel, J.M., (2001). Rule-Based Fuzzy Logic Systems: Introduction and New Directions. Prentice-Hall, Englewood Cliffs, NJ.

Mendel, J., (2004). Fuzzy Sets for Words: Why Type-2 Fuzzy Sets Should be Used and How They Can be Used. IEEE FUZZ in Budapest Hungary.

Mendel, J., (2006). Interval Type 2 Fuzzy Logic Systems Made Simple. IEEE Transactions on Fuzzy Systems, 14(6):808-821.

Robertson, K. (2005). 10 Characteristics of Successful Salespeople. Retrieved May 28, 2011, from business know-how. Web site:

http://www.businessknowhow.com/marketing/successful-salesperson.htm

Ruth, A. \& Wysocki, A. (2008). Top Sellers: Characteristics of a Superior Salesperson. Food and Resource Economics Department, Florida Cooperative Extension Service, Institute of Food and Agricultural Sciences.

Sardar, A., \& Patton, M.A. What makes a great salesperson?: Links between our heritage and the future. Retrieved February 7, 2002 from the Internet. Site cannot be linked. Web address: http://130.195.95.71:8081/www/ANZMAC1999/Site/S/Sardar.pdf

Tibrewala, R., Philippe, D., Brown, J. (1972). Optimal scheduling of two consecutive idle periods, Management Science. 19 (1) 71-75

Tizhoosh, H. R. (2004). Introduction of Fuzzy Systems, Fuzzy image processing. Retrieved May 28, 2011. Web Site: http://pami.uwaterloo.ca/tizhoosh/Turotial2.htm 
Winston, W. (2003). Operations Research: Applications and Algorithms $4^{\text {th }}$ Edition, Duxbury Press, Pacific Grove, CA.

Zadeh, L. A., Fuzzy Sets, Information and Control, Vol. 8, 1965, p 338-353.

Zadeh, L. A., (1975). The Concept of Linguistic Variable and its Application to Approximate Reasoning -I, 11,111, Information Sciences, 1975, Vol. 8. p 199-249, Vol. 8, p 301-357, Vol. 9, p 43-80.

Zadeh, L. A., (1983). The Role of Fuzzy Logic in the Management of Uncertainty in ExpertSystems, Fuzzv Sets and Svstems, Vol. 11, p 199-227.

Zadeh, L., (1985). Fuzzy Sets, Usuality and Commonsense Reasoning, EECS Technical Report, University of California, Berkeley.

Zadeh, L., (1992). The Calculus of Fuzzy IF/THEN Rules, March, p. 23-27.

Zadeh, L. (1994). Fuzzy Logic, Neural Networks, and Soft Computing, Communications of the ACM . Vol 37 No.3 
APPENDICES 


\section{APPENDIX A}

\section{Membership Function Intersections}

Rule: IF "Length of line" is Really Long AND "Num. of Item's" is Around 20AND "Checker" is Human AND "Need to leave" is Emergency THEN Do Not Pick Line.
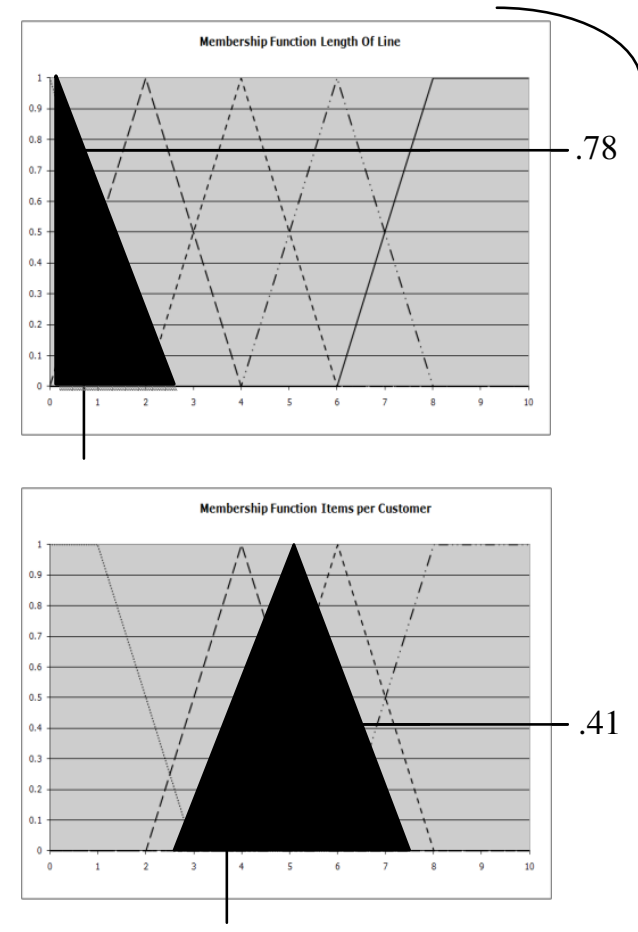

Taking the min (.41).
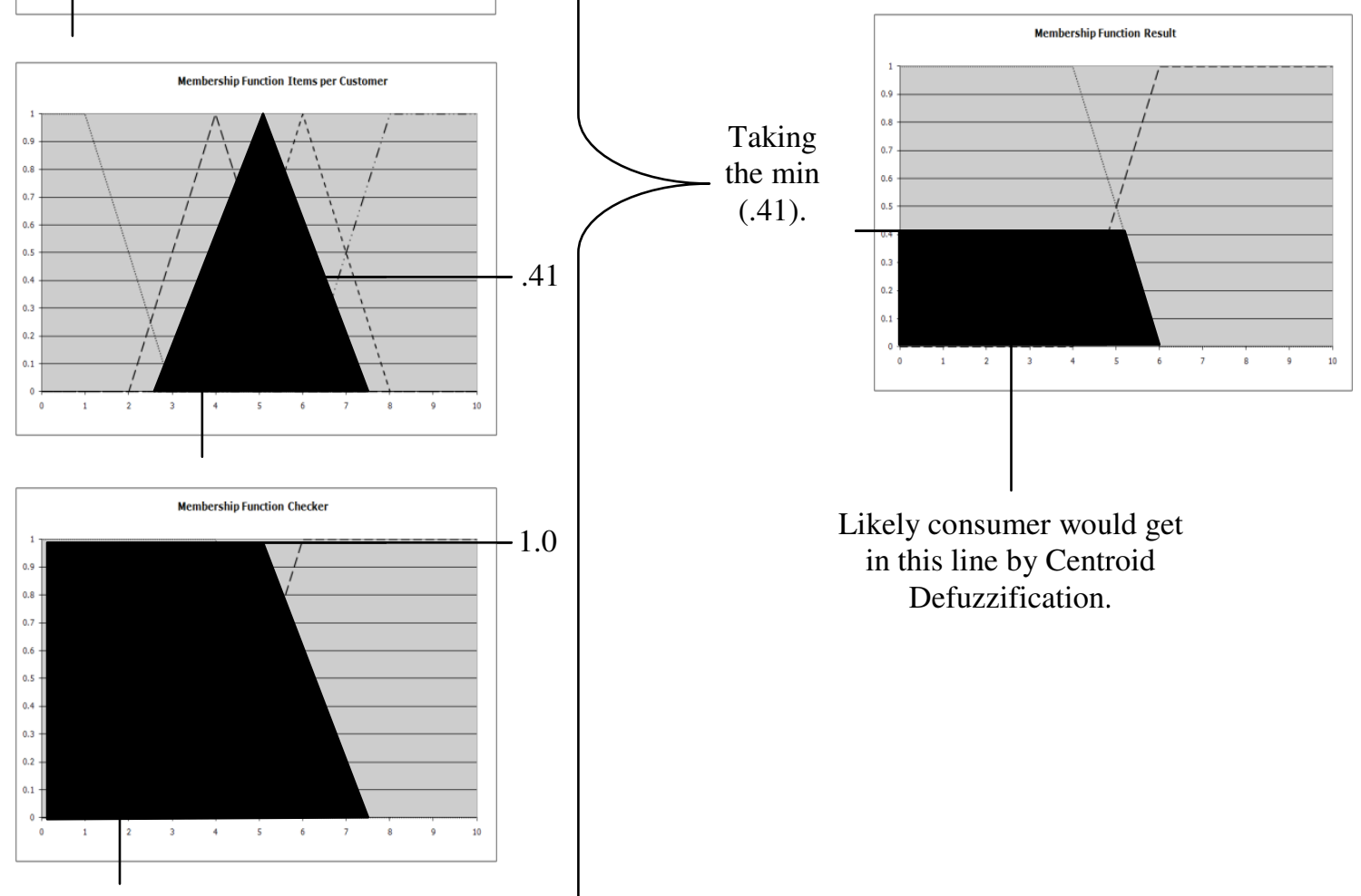

Likely consumer would get in this line by Centroid Defuzzification.

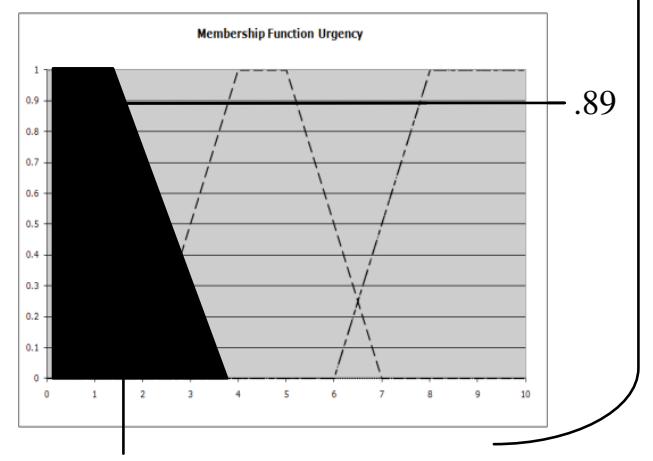


APPENDIX B

Energy Level Membership Function

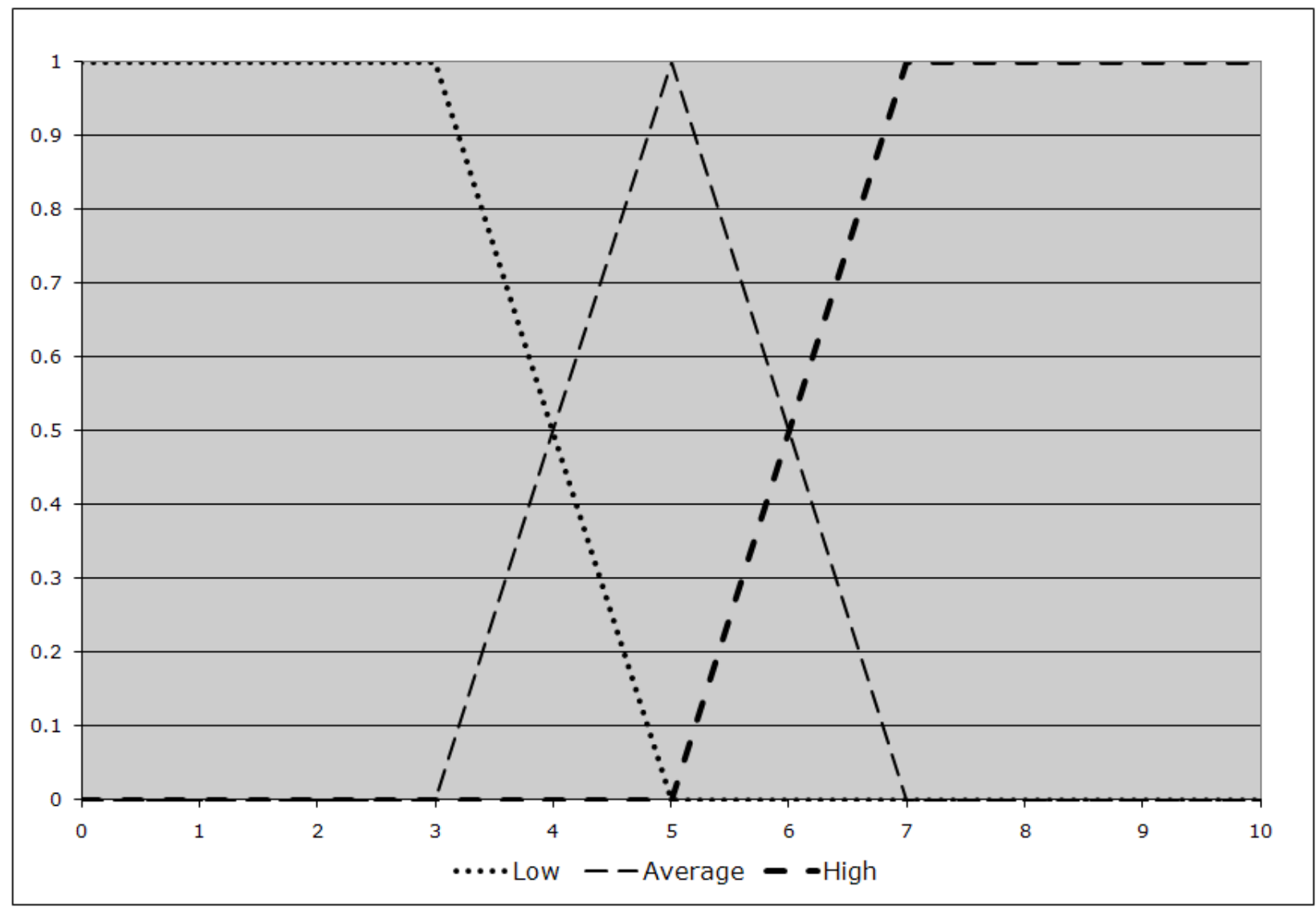




\section{APPENDIX C}

\section{Experience Membership Function}

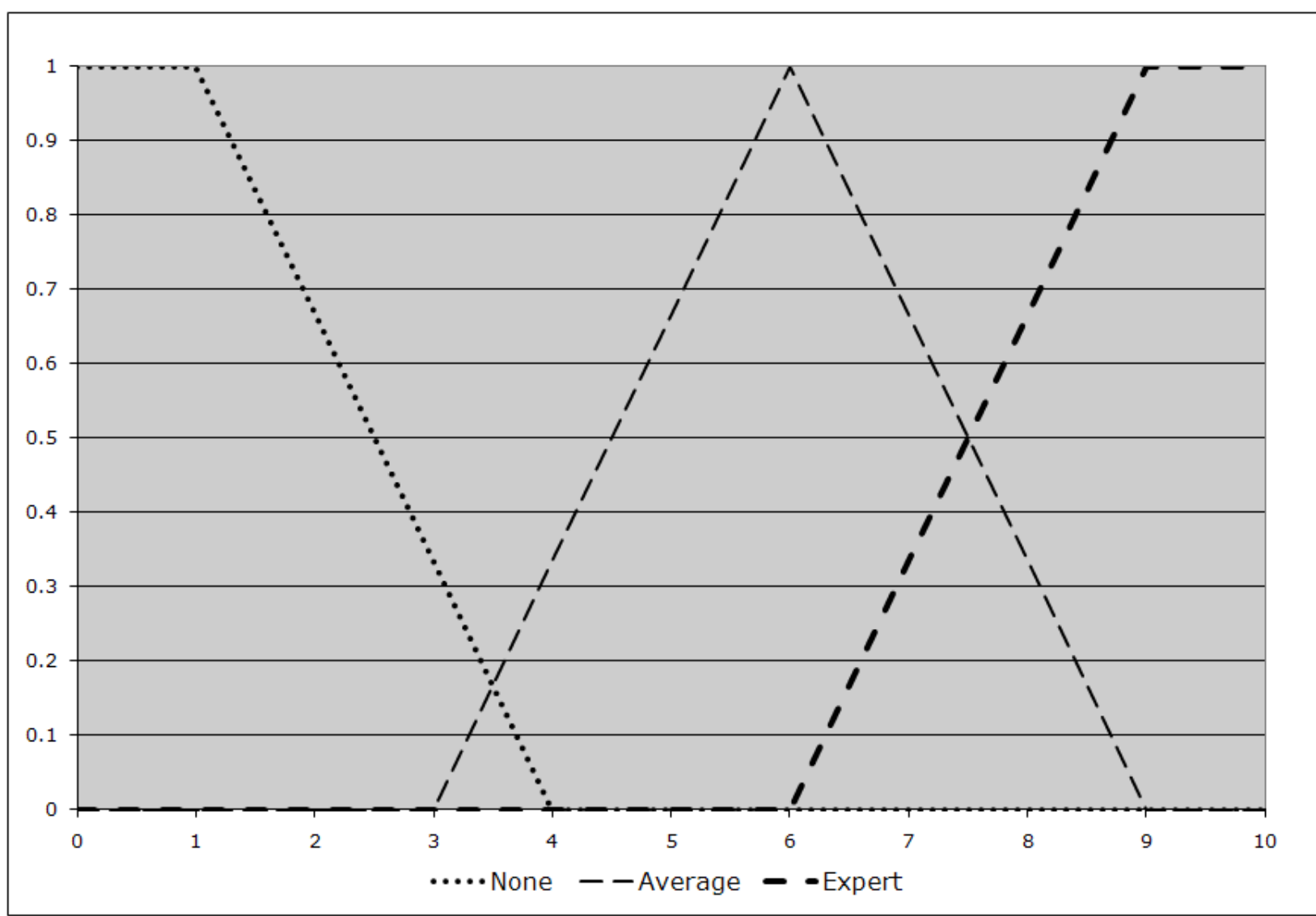




\section{APPENDIX D}

\section{Personality Membership Function}

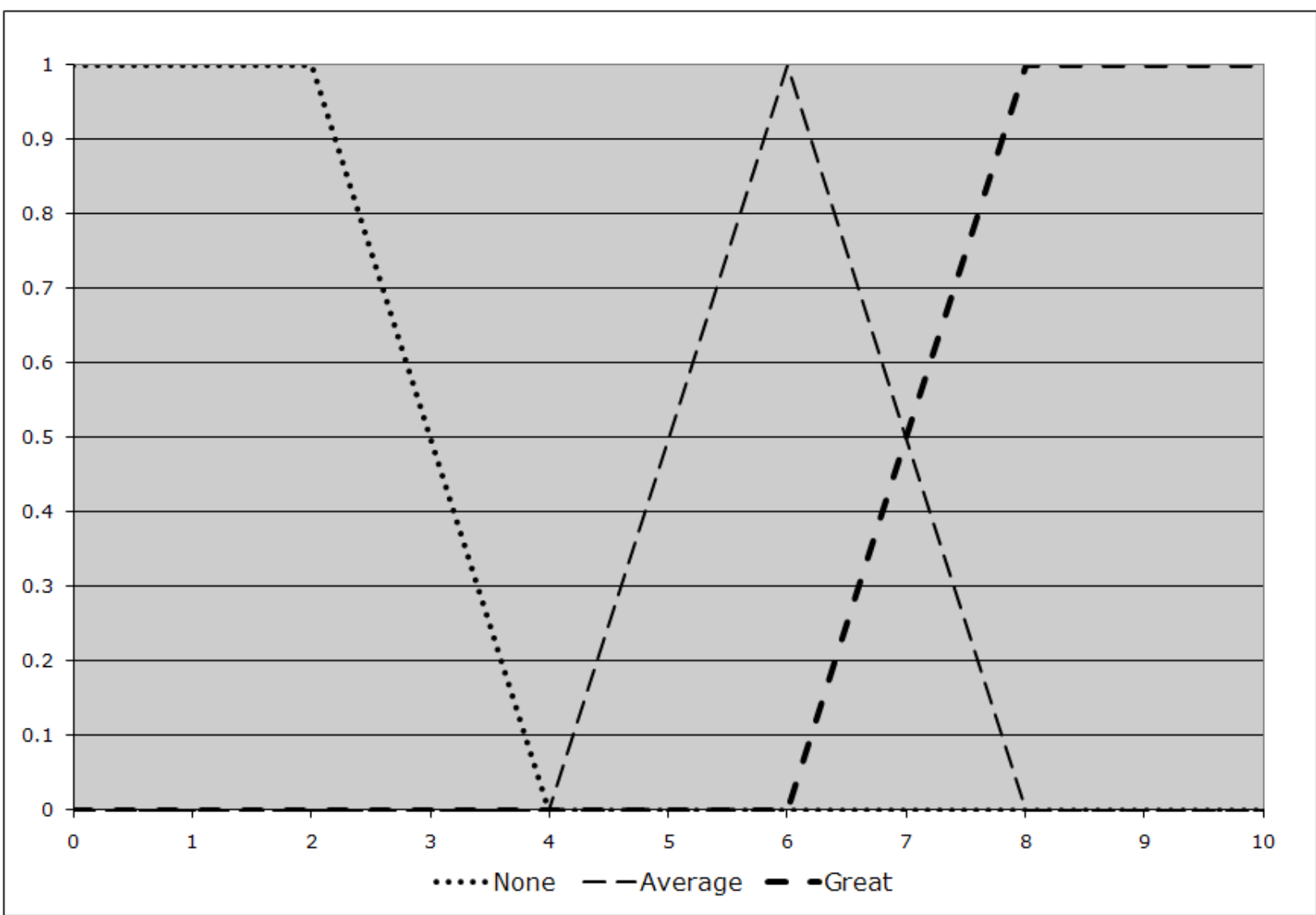




\section{APPENDIX E}

\section{Self-Confidence Membership Function}

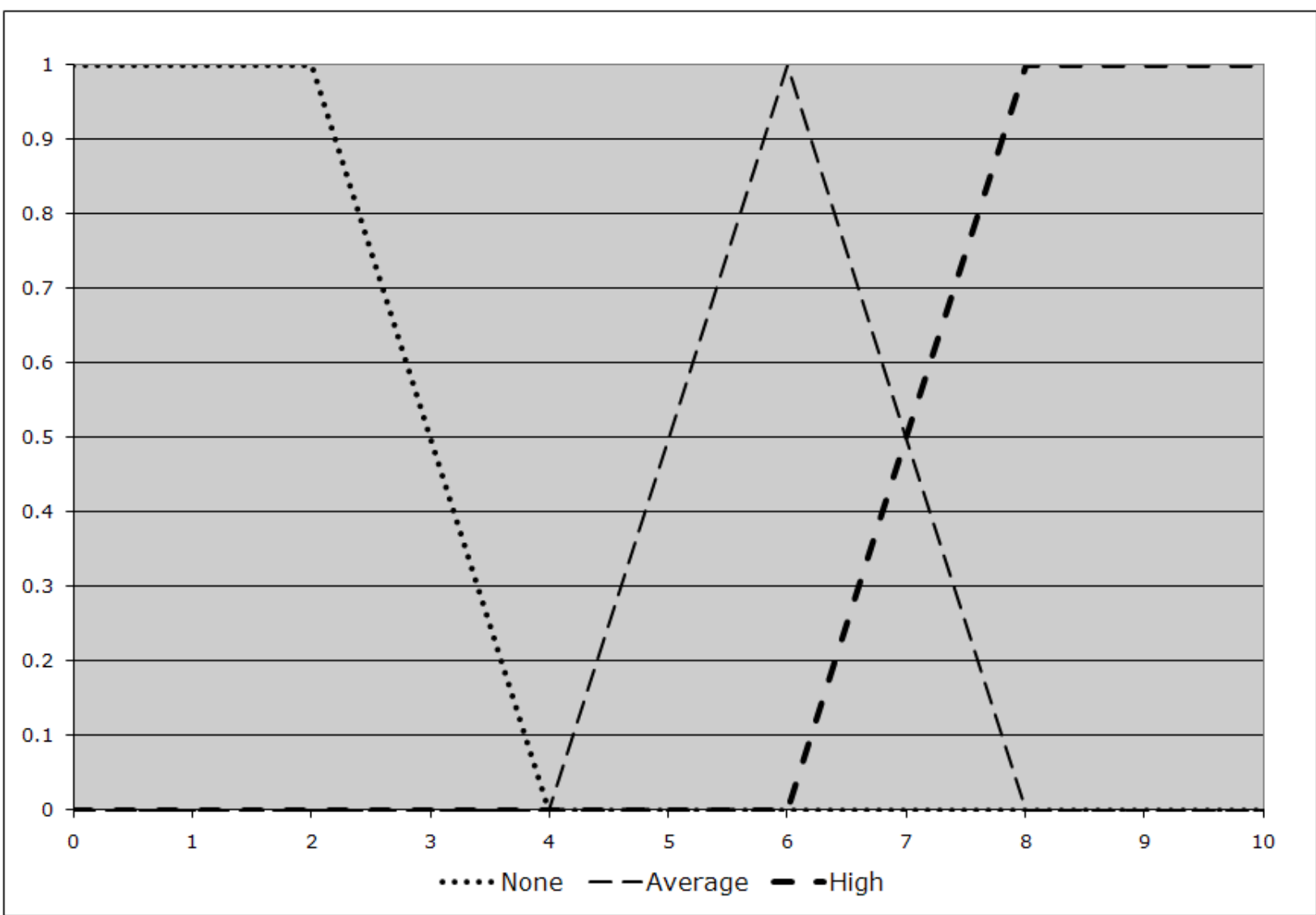




\section{APPENDIX F}

\section{Communication Skills Membership Function}

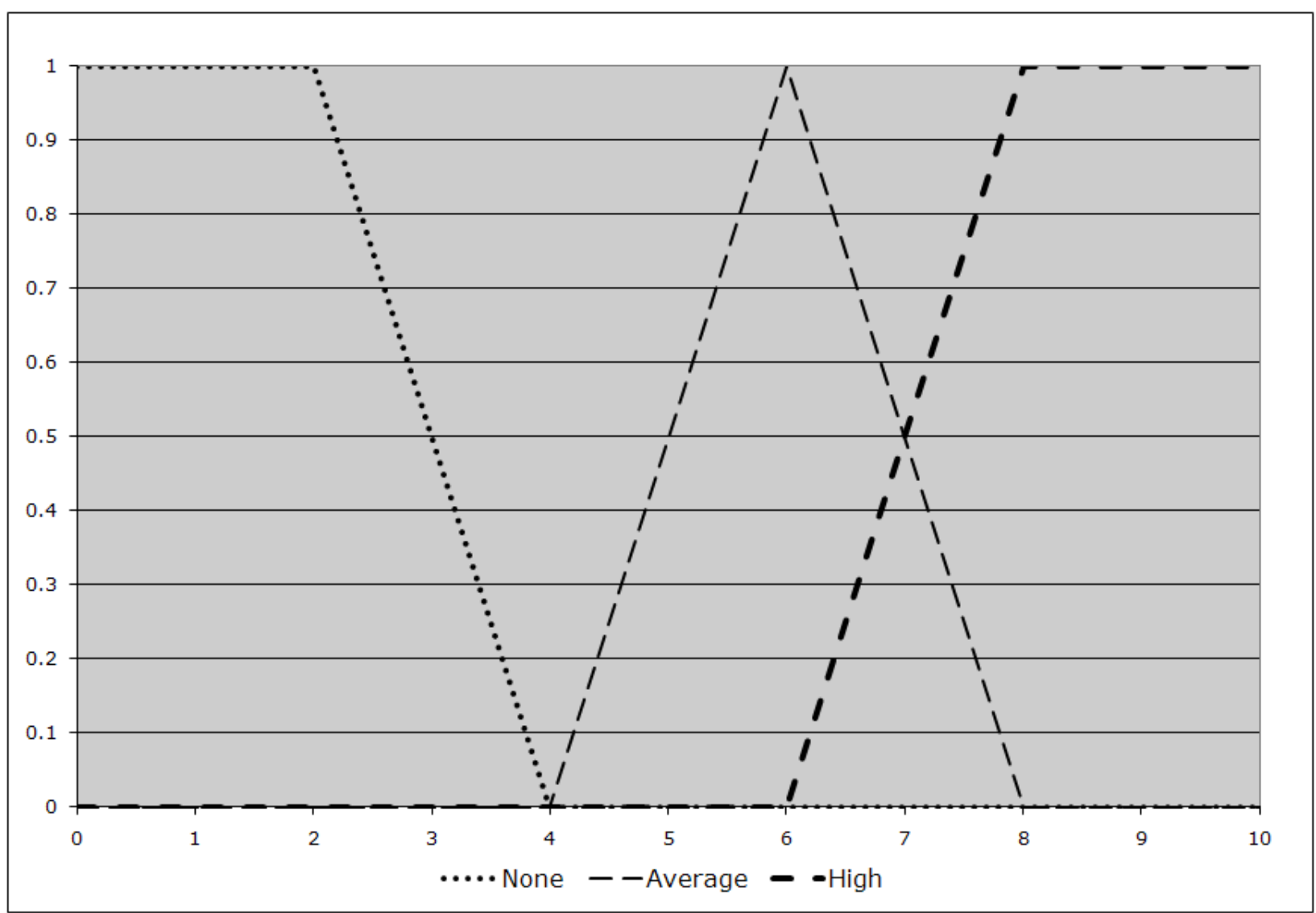




\section{APPENDIX G}

\section{Commitment Membership Function}

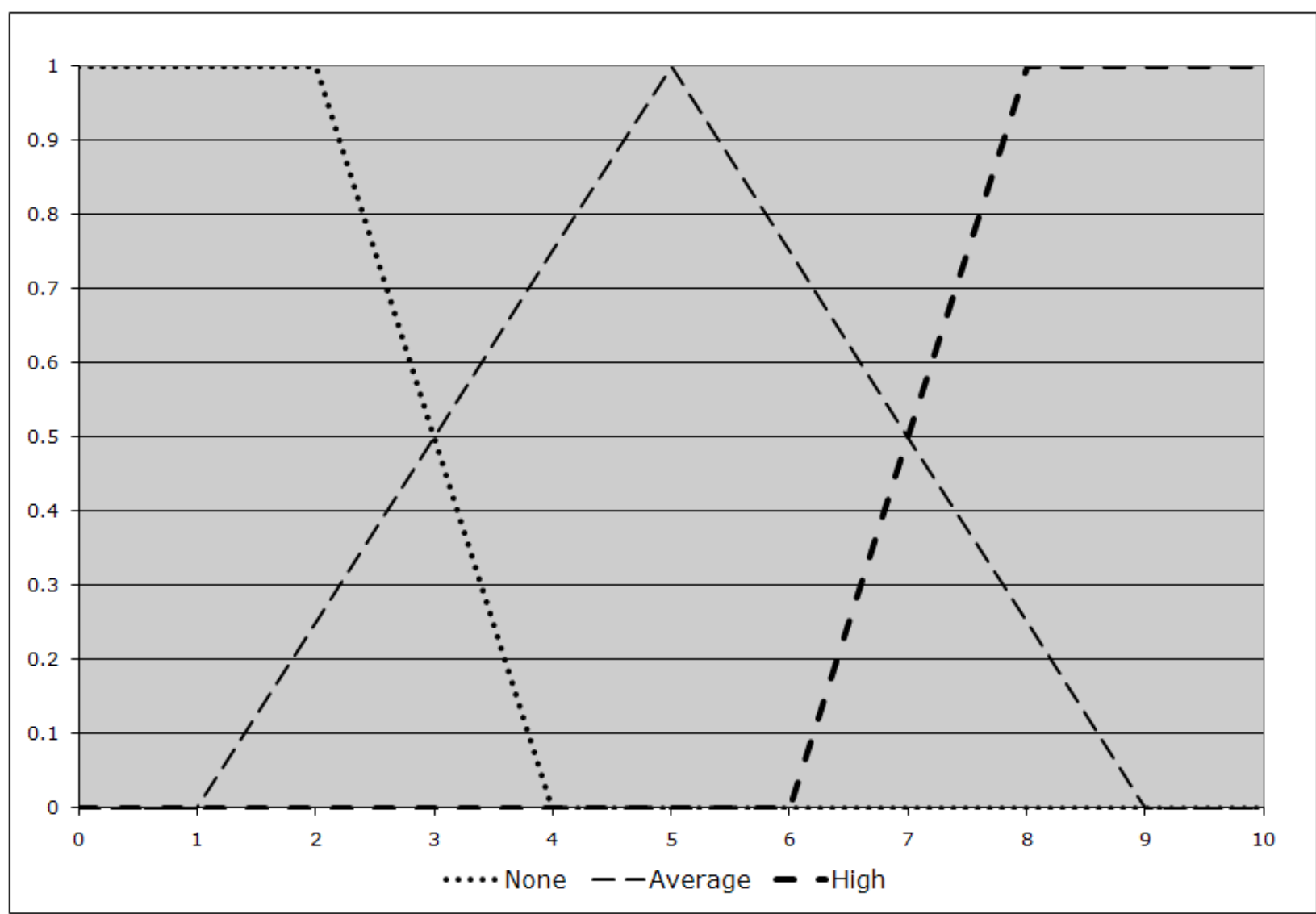




\section{APPENDIX H}

\section{Result Membership Function}

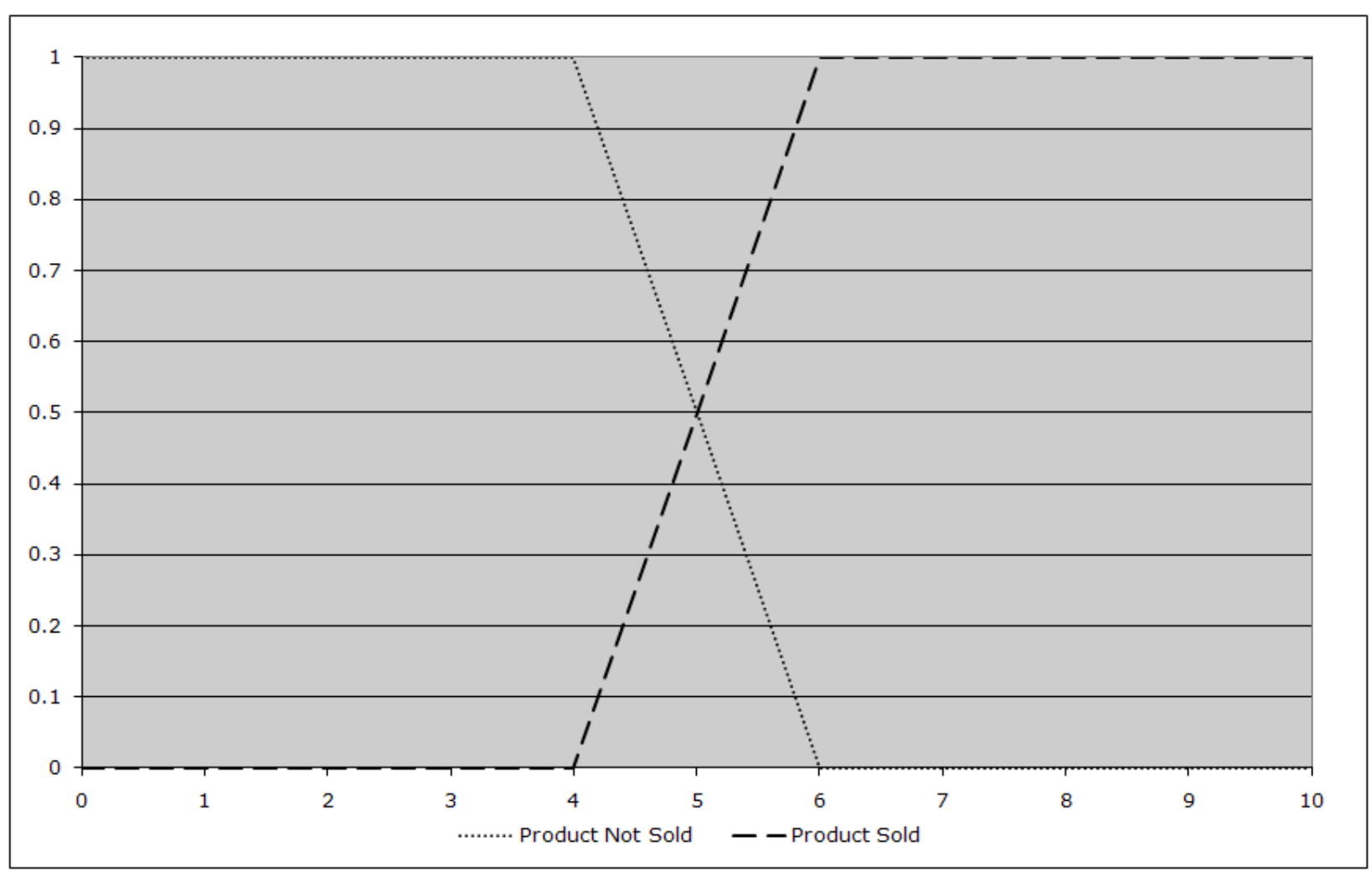




\section{APPENDIX I}

\section{Relative Likelihood of Closing a Sale}

\begin{tabular}{|c|c|c|c|c|c|c|c|}
\hline & $\begin{array}{c}\text { Energy } \\
\text { Level }\end{array}$ & Experience & Personality & $\begin{array}{c}\text { Self- } \\
\text { Confidence }\end{array}$ & $\begin{array}{l}\text { Communication } \\
\text { Skills }\end{array}$ & Commitment & $\begin{array}{l}\text { Likelihood of } \\
\text { Making Sale }\end{array}$ \\
\hline \multicolumn{8}{|c|}{ Lookie Lou } \\
\hline \multirow{11}{*}{ 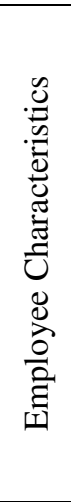 } & 0 & 0 & 0 & 0 & 0 & 0 & $3 \%$ \\
\hline & 1 & 1 & 1 & 1 & 1 & 1 & $3 \%$ \\
\hline & 2 & 2 & 2 & 2 & 2 & 2 & $4 \%$ \\
\hline & 3 & 3 & 3 & 3 & 3 & 3 & $6 \%$ \\
\hline & 4 & 4 & 4 & 4 & 4 & 4 & $14 \%$ \\
\hline & 5 & 5 & 5 & 5 & 5 & 5 & $15 \%$ \\
\hline & 6 & 6 & 6 & 6 & 6 & 6 & $18 \%$ \\
\hline & 7 & 7 & 7 & 7 & 7 & 7 & $30 \%$ \\
\hline & 8 & 8 & 8 & 8 & 8 & 8 & $41 \%$ \\
\hline & 9 & 9 & 9 & 9 & 9 & 9 & $45 \%$ \\
\hline & 10 & 10 & 10 & 10 & 10 & 10 & $45 \%$ \\
\hline \multicolumn{8}{|c|}{ Price Shopper } \\
\hline \multirow{11}{*}{ 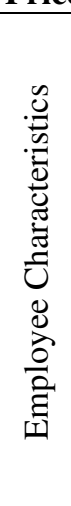 } & 0 & 0 & 0 & 0 & 0 & 0 & $3 \%$ \\
\hline & 1 & 1 & 1 & 1 & 1 & 1 & $3 \%$ \\
\hline & 2 & 2 & 2 & 2 & 2 & 2 & $4 \%$ \\
\hline & 3 & 3 & 3 & 3 & 3 & 3 & $15 \%$ \\
\hline & 4 & 4 & 4 & 4 & 4 & 4 & $33 \%$ \\
\hline & 5 & 5 & 5 & 5 & 5 & 5 & $35 \%$ \\
\hline & 6 & 6 & 6 & 6 & 6 & 6 & $38 \%$ \\
\hline & 7 & 7 & 7 & 7 & 7 & 7 & $54 \%$ \\
\hline & 8 & 8 & 8 & 8 & 8 & 8 & $71 \%$ \\
\hline & 9 & 9 & 9 & 9 & 9 & 9 & $75 \%$ \\
\hline & 10 & 10 & 10 & 10 & 10 & 10 & $75 \%$ \\
\hline \multicolumn{8}{|c|}{ Buyer } \\
\hline \multirow{11}{*}{ 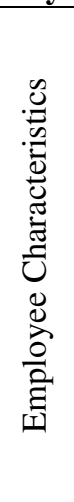 } & 0 & 0 & 0 & 0 & 0 & 0 & $5 \%$ \\
\hline & 1 & 1 & 1 & 1 & 1 & 1 & $5 \%$ \\
\hline & 2 & 2 & 2 & 2 & 2 & 2 & $8 \%$ \\
\hline & 3 & 3 & 3 & 3 & 3 & 3 & $33 \%$ \\
\hline & 4 & 4 & 4 & 4 & 4 & 4 & $48 \%$ \\
\hline & 5 & 5 & 5 & 5 & 5 & 5 & $51 \%$ \\
\hline & 6 & 6 & 6 & 6 & 6 & 6 & $61 \%$ \\
\hline & 7 & 7 & 7 & 7 & 7 & 7 & $86 \%$ \\
\hline & 8 & 8 & 8 & 8 & 8 & 8 & $93 \%$ \\
\hline & 9 & 9 & 9 & 9 & 9 & 9 & $95 \%$ \\
\hline & 10 & 10 & 10 & 10 & 10 & 10 & $95 \%$ \\
\hline
\end{tabular}




\section{APPENDIX J}

\section{Detailed LP formulation}

Objective Function:

$$
\begin{aligned}
& \mathrm{Max} Z=\sum(\mathrm{w}=1-28) \mathrm{ES}_{\mathrm{iw}} * \mathrm{X}_{\mathrm{iw}}+\mathrm{ES}_{\mathrm{iw}+1} * \mathrm{X}_{\mathrm{iw}}(\mathrm{i}=1, \ldots, 5) \\
& \left(\left(\mathrm{ES}_{1-1} * \mathrm{X}_{1-1}\right)+\left(\mathrm{ES}_{1-2} * \mathrm{X}_{1-1}\right)\right)+\left(\left(\mathrm{ES}_{1-2} * \mathrm{X}_{1-2}\right)+\left(\mathrm{ES}_{1-3} * \mathrm{X}_{1-2}\right)\right)+ \\
& \left(\left(\mathrm{ES}_{1-3} * \mathrm{X}_{1-3}\right)+\left(\mathrm{ES}_{1-4} * \mathrm{X}_{1-3}\right)\right)+\left(\left(\mathrm{ES}_{1-5} * \mathrm{X}_{1-5}\right)+\left(\mathrm{ES}_{1-6} * \mathrm{X}_{1-5}\right)\right)+ \\
& \left(\left(\mathrm{ES}_{1-6} * \mathrm{X}_{1-6}\right)+\left(\mathrm{ES}_{1-7} * \mathrm{X}_{1-6}\right)\right)+\left(\left(\mathrm{ES}_{1-7} * \mathrm{X}_{1-7}\right)+\left(\mathrm{ES}_{1-8} * \mathrm{X}_{1-7}\right)\right)+ \\
& \left(\left(\mathrm{ES}_{1-9} * \mathrm{X}_{1-9}\right)+\left(\mathrm{ES}_{1-10} * \mathrm{X}_{1-9}\right)\right)+\left(\left(\mathrm{ES}_{1-10} * \mathrm{X}_{1-10}\right)+\left(\mathrm{ES}_{1-11} * \mathrm{X}_{1-10}\right)\right)+ \\
& \left(\left(\mathrm{ES}_{1-11} * \mathrm{X}_{1-11}\right)+\left(\mathrm{ES}_{1-12} * \mathrm{X}_{1-11}\right)\right)+\left(\left(\mathrm{ES}_{1-13} * \mathrm{X}_{1-13}\right)+\left(\mathrm{ES}_{1-14} * \mathrm{X}_{1-13}\right)\right)+ \\
& \left(\left(\mathrm{ES}_{1-14} * \mathrm{X}_{1-14}\right)+\left(\mathrm{ES}_{1-15} * \mathrm{X}_{1-14}\right)\right)+\left(\left(\mathrm{ES}_{1-15} * \mathrm{X}_{1-15}\right)+\left(\mathrm{ES}_{1-16} * \mathrm{X}_{1-15}\right)\right)+ \\
& \left(\left(\mathrm{ES}_{1-17} * \mathrm{X}_{1-17}\right)+\left(\mathrm{ES}_{1-18} * \mathrm{X}_{1-17}\right)\right)+\left(\left(\mathrm{ES}_{1-18} * \mathrm{X}_{1-18}\right)+\left(\mathrm{ES}_{1-19} * \mathrm{X}_{1-18}\right)\right)+ \\
& \left(\left(\mathrm{ES}_{1-19} * \mathrm{X}_{1-19}\right)+\left(\mathrm{ES}_{1-20} * \mathrm{X}_{1-19}\right)\right)+\left(\left(\mathrm{ES}_{1-21} * \mathrm{X}_{1-21}\right)+\left(\mathrm{ES}_{1-22} * \mathrm{X}_{1-21}\right)\right)+
\end{aligned}
$$$$
\left(\left(\mathrm{ES}_{1-22} * \mathrm{X}_{1-22}\right)+\left(\mathrm{ES}_{1-23} * \mathrm{X}_{1-22}\right)\right)+\left(\left(\mathrm{ES}_{1-23} * \mathrm{X}_{1-23}\right)+\left(\mathrm{ES}_{1-24} * \mathrm{X}_{1-23}\right)\right)+
$$$$
\left(\left(\mathrm{ES}_{1-25} * \mathrm{X}_{1-25}\right)+\left(\mathrm{ES}_{1-26} * \mathrm{X}_{1-25}\right)\right)+\left(\left(\mathrm{ES}_{1-26} * \mathrm{X}_{1-26}\right)+\left(\mathrm{ES}_{1-27} * \mathrm{X}_{1-26}\right)\right)+
$$$$
\left(\left(\mathrm{ES}_{1-27} * \mathrm{X}_{1-27}\right)+\left(\mathrm{ES}_{1-28} * \mathrm{X}_{1-27}\right)\right)
$$

$* \mathrm{X}_{1-4}, \mathrm{X}_{1-8}, \mathrm{X}_{1-12}, \mathrm{X}_{1-16}, \mathrm{X}_{1-20}, \mathrm{X}_{1-24}$ and $\mathrm{X}_{1-28}$ are not used because a salesperson can't start a their shift on the fourth shift of the day.

* Above is just for Salesperson 1 over the 28 shifts. This would be repeated for each Salesperson.

\section{Constants:}

Estimated Sales:

$$
\mathrm{ES}_{\mathrm{iw}}=\left(\left(\mathrm{A}_{\mathrm{iLL}} * \mathrm{P}_{\mathrm{LLw}}\right)+\left(\mathrm{A}_{\mathrm{iPS}} * \mathrm{P}_{\mathrm{PSw}}\right)+\left(\mathrm{A}_{\mathrm{iB}} * \mathrm{P}_{\mathrm{Bw}}\right)\right) * \mathrm{~N}_{\mathrm{w}}
$$

Constraints: 
Max number of days worked:

$$
\begin{aligned}
& \sum(w=1 \text { to } 28) X_{i w} \leq 5 \text { for } i=1, \ldots, 5 \\
& X_{1-1}+X_{1-2}+X_{1-3}+X_{1-4}+X_{1-5}+X_{1-6}+X_{1-7}+X_{1-8}+X_{1-9}+X_{1-10}+X_{1-11}+ \\
& X_{1-12}+X_{1-13}+X_{1-14}+X_{1-15}+X_{1-16}+X_{1-17}+X_{1-18}+X_{1-19}+X_{1-20}+X_{1-21}+ \\
& X_{1-22}+X_{1-23}+X_{1-24}+X_{1-25}+X_{1-26}+X_{1-27}+X_{1-28} \leq 5
\end{aligned}
$$

*Above is just for Salesperson 1 over the 28 shifts. This would be repeated for each Salesperson.

Force employees to work 2 consecutive shifts:

$$
\begin{array}{r}
X_{i 1}+X_{i 2}+X_{i 3} \leq 1 \text { for } i=1, \ldots, 5 \\
X_{1-1}+X_{1-2}+X_{1-3} \leq 1 \\
X_{2-1}+X_{2-2}+X_{2-3} \leq 1 \\
X_{3-1}+X_{3-2}+X_{3-3} \leq 1 \\
X_{4-1}+X_{4-2}+X_{4-3} \leq 1 \\
X_{5-1}+X_{5-2}+X_{5-3} \leq 1 \\
X_{i 5}+X_{i 6}+X_{i 7} \leq 1 \text { for } i=1, \ldots, 5 \\
X_{1-5}+X_{1-6}+X_{1-7} \leq 1 \\
X_{2-5}+X_{2-6}+X_{2-7} \leq 1 \\
X_{3-5}+X_{3-6}+X_{3-7} \leq 1 \\
X_{4-5}+X_{4-6}+X_{4-7} \leq 1 \\
X_{5-5}+X_{5-6}+X_{5-7} \leq 1 \\
X_{i 9}+X_{i 10}+X_{i 11} \leq 1 \text { for } i=1, \ldots, 5 \\
X_{1-9}+X_{1-10}+X_{1-11} \leq 1 \\
X_{2-9}+X_{2-10}+X_{2-11} \leq 1
\end{array}
$$




$$
\begin{aligned}
& X_{3-9}+X_{3-10}+X_{3-11} \leq 1 \\
& \mathrm{X}_{4-9}+\mathrm{X}_{4-10}+\mathrm{X}_{4-11} \leq 1 \\
& X_{5-9}+X_{5-10}+X_{5-11} \leq 1 \\
& \mathrm{X}_{\mathrm{i} 13}+\mathrm{X}_{\mathrm{i} 14}+\mathrm{X}_{\mathrm{i} 15} \leq 1 \text { for } \mathrm{i}=1, \ldots, 5 \\
& \mathrm{X}_{1-13}+\mathrm{X}_{1-14}+\mathrm{X}_{1-15} \leq 1 \\
& \mathrm{X}_{2-13}+\mathrm{X}_{2-14}+\mathrm{X}_{2-15} \leq 1 \\
& \mathrm{X}_{3-13}+\mathrm{X}_{3-14}+\mathrm{X}_{3-15} \leq 1 \\
& \mathrm{X}_{4-13}+\mathrm{X}_{4-14}+\mathrm{X}_{4-15} \leq 1 \\
& \mathrm{X}_{5-13}+\mathrm{X}_{5-14}+\mathrm{X}_{5-15} \leq 1 \\
& \mathrm{X}_{\mathrm{i} 17}+\mathrm{X}_{\mathrm{i} 18}+\mathrm{X}_{\mathrm{i} 19} \leq 1 \text { for } \mathrm{i}=1, \ldots, 5 \\
& \mathrm{X}_{1-17}+\mathrm{X}_{1-18}+\mathrm{X}_{1-19} \leq 1 \\
& \mathrm{X}_{2-17}+\mathrm{X}_{2-18}+\mathrm{X}_{2-19} \leq 1 \\
& \mathrm{X}_{3-17}+\mathrm{X}_{3-18}+\mathrm{X}_{3-19} \leq 1 \\
& \mathrm{X}_{4-17}+\mathrm{X}_{4-18}+\mathrm{X}_{4-19} \leq 1 \\
& \mathrm{X}_{5-17}+\mathrm{X}_{5-18}+\mathrm{X}_{5-19} \leq 1 \\
& \mathrm{X}_{\mathrm{i} 21}+\mathrm{X}_{\mathrm{i} 22}+\mathrm{X}_{\mathrm{i} 23} \leq 1 \text { for } \mathrm{i}=1, \ldots, 5 \\
& \mathrm{X}_{1-21}+\mathrm{X}_{1-22}+\mathrm{X}_{1-23} \leq 1 \\
& \mathrm{X}_{2-21}+\mathrm{X}_{2-22}+\mathrm{X}_{2-23} \leq 1 \\
& \mathrm{X}_{3-21}+\mathrm{X}_{3-22}+\mathrm{X}_{3-23} \leq 1 \\
& \mathrm{X}_{4-21}+\mathrm{X}_{4-22}+\mathrm{X}_{4-23} \leq 1 \\
& \mathrm{X}_{5-21}+\mathrm{X}_{5-22}+\mathrm{X}_{5-23} \leq 1 \\
& \mathrm{X}_{\mathrm{i} 25}+\mathrm{X}_{\mathrm{i} 26}+\mathrm{X}_{\mathrm{i} 27} \leq 1 \text { for } \mathrm{i}=1, \ldots, 5 \\
& \mathrm{X}_{1-25}+\mathrm{X}_{1-26}+\mathrm{X}_{1-27} \leq 1
\end{aligned}
$$




$$
\begin{aligned}
& X_{2-25}+X_{2-26}+X_{2-27} \leq 1 \\
& X_{3-25}+X_{3-26}+X_{3-27} \leq 1 \\
& X_{4-25}+X_{4-26}+X_{4-27} \leq 1 \\
& X_{5-25}+X_{5-26}+X_{5-27} \leq 1
\end{aligned}
$$

Minimum number of employees per shift:

Working shift 1 (Starting shift 1)

$\sum(\mathrm{i}=1$ to 5$) \mathrm{X}_{\mathrm{iw}} \geq \mathrm{D}_{\mathrm{w}}$ for $\mathrm{w}=1,5,9,13,17,21,25$

$$
X_{1-1}+X_{2-1}+X_{3-1}+X_{4-1}+X_{5-1} \geq D_{1}
$$

*Above is just for Salesperson 1 during shift 1 . This would be repeated for the remaining shifts $(\mathrm{w})$.

Working shift $1 \& 2$ (Ending shift 2)

$\sum(\mathrm{i}=1$ to 5$) \mathrm{X}_{\mathrm{iw}-1}+\mathrm{X}_{\mathrm{iw}} \geq \mathrm{D}_{\mathrm{w}}$ for $\mathrm{w}=2,6,10,14,18,22,26$

$$
\left(X_{1-1}+X_{1-2}\right)+\left(X_{2-1}+X_{2-2}\right)+\left(X_{3-1}+X_{3-2}\right)+\left(X_{4-1}+X_{4-2}\right)+\left(X_{5-1}+X_{5-2}\right) \geq D_{2}
$$

*Above is just for Salesperson 1 during shift 2. This would be repeated for the remaining shifts $(\mathrm{w})$.

Working shift $2 \& 3$ (Starting shift 2)

$\sum(\mathrm{i}=1$ to 5$) \mathrm{X}_{\mathrm{iw}-1}+\mathrm{X}_{\mathrm{iw}} \geq \mathrm{D}_{\mathrm{w}}$ for $\mathrm{w}=3,7,11,15,19,23,27$

$\left(X_{1-2}+X_{1-3}\right)+\left(X_{2-2}+X_{2-3}\right)+\left(X_{3-2}+X_{3-3}\right)+\left(X_{4-2}+X_{4-3}\right)+\left(X_{5-2}+X_{5-3}\right) \geq D_{3}$

*Above is just for Salesperson 1 during shift 3. This would be repeated for the remaining shifts (w).

Working shift $3 \& 4$ (Starting shift 3)

$\sum(\mathrm{i}=1$ to 5$) \mathrm{X}_{\mathrm{iw}} \geq \mathrm{D}_{\mathrm{w}+1}$ for $\mathrm{w}=3,7,11,15,19,23,27$

$X_{1-3}+X_{2-3}+X_{3-3}+X_{4-3}+X_{5-3} \geq D_{4}$

*Above is just for Salesperson 1 during shift 3. This would be repeated for the remaining shifts (w). 